\title{
Increasing access to safe abortion in rural Rajasthan: Outcomes of a comprehensive abortion care model
}

Shireen J. Jejeebhoy Population Council

A.J. Francis Zavier

Population Council

Rajib Acharya

Population Council

Shveta Kalyanwala

Population Council

Follow this and additional works at: https://knowledgecommons.popcouncil.org/departments_sbsr-rh

Part of the Demography, Population, and Ecology Commons, Family, Life Course, and Society Commons, International Public Health Commons, Public Health Education and Promotion Commons, and the Women's Health Commons

How does access to this work benefit you? Let us know!

\section{Recommended Citation}

Jejeebhoy, Shireen J., A.J. Francis Zavier, Rajib Acharya, and Shveta Kalyanwala. 2011. "Increasing access to safe abortion in rural Rajasthan: Outcomes of a comprehensive abortion care model." New Delhi:

Population Council. 
The Consortium for Safe Abortions in India, comprising Ipas (Coordinating Partner), Action Research and Training for Health (ARTH), the Centre for Enquiry into Health and Allied Themes (CEHAT), the Family Planning Association of India (FPAI), Federation of Obstetric and Gynaecological Societies of India (FOGSI), International Maternal and Child Health (IMCH)-Uppsala University, the Population Council and the Society of Midwives, India (SOMI), was established with the goal of increasing the ability of rural women to acquire accessible and high quality abortion services. One of its key activities was to develop and implement a comprehensive and evidence-based abortion care model for rural women that addressed both facility-based and community-based barriers to safe abortion, that focused on enabling public sector sites to offer comprehensive abortion care services and simultaneously, to build awareness at woman- and community-levels about the legality of abortion and the availability of safe abortion services in the public sector. The model was developed and implemented by Consortium partner, the Family Planning Association of India, in one district of Rajasthan, namely, Tonk. The Population Council conducted an assessment of the effectiveness of this model in improving the availability and quality of abortion services in public sector facilities, and women's awareness and experiences with regard to abortion services. This report presents a description of the model and the findings of the assessment.

For additional copies of this report, please contact:

Population Council

Zone 5-A, Ground Floor

India Habitat Centre

Lodi Road

New Delhi 110003

Phone: 011-2464 2901/02

email: info.india@popcouncil.org

Web site: http://www.popcouncil.org/asia/india.html

The Population Council is an international, non-profit, non-governmental organisation that seeks to improve the well-being and reproductive health of current and future generations around the world and to help achieve a humane, equitable and sustainable balance between people and resources. The Council conducts biomedical, social science and public health research, and helps build research capacities in developing countries.

Copyright $@ 2011$ Population Council

Suggested citation: Jejeebhoy, S. J., A. J. Francis Zavier, R. Acharya and S. Kalyanwala. 2011. Increasing access to safe abortion in rural Rajasthan: Outcomes of a Comprehensive Abortion Care model. New Delhi: Population Council. 




\section{The Consortium for Safe Abortions in India}

\section{Consortium partners:}

Ipas (Coordinating Partner)

Action Research and Training for Health (ARTH)

Centre for Enquiry into Health and Allied Themes (CEHAT)

Family Planning Association of India (FPAI)

Federation of Obstetric and Gynaecological Societies of India (FOGSI)

International Maternal and Child Health (IMCH)-Uppsala University

Population Council

Society of Midwives, India (SOMI)

The Consortium was supported by:

The Swedish International Development Cooperation Agency (Sida)

The David and Lucile Packard Foundation 



\section{Contents}

List of tables

\begin{tabular}{ll} 
Acknowledgements & ix \\
\hline
\end{tabular}

Chapter 1 Introduction 1

Context 1

Study objectives $\quad 1$

Background 2

$\begin{array}{ll}\text { Setting } & 4\end{array}$

Study design and samples $\quad 5$

$\begin{array}{ll}\text { Instruments } & 7\end{array}$

$\begin{array}{ll}\text { Analysis } & 8\end{array}$

$\begin{array}{ll}\text { Response rates } & 8\end{array}$

Structure of this report 9

Chapter 2 Characteristics of health facilities and social and demographic profiles of households and respondents 10

$\begin{array}{ll}\text { Health facilities } & 10\end{array}$

Community survey 15

Characteristics of households 16

Background characteristics of respondents 16

Awareness and perceptions of respondents about abortion, facilities and providers 17

$\begin{array}{ll}\text { Prevalence and experiences of abortion } & 18\end{array}$

Chapter 3 The Comprehensive Abortion Care model 23

$\begin{array}{ll}\text { Objectives } & 23\end{array}$

Setting 24

Implementation $\quad 24$

Facility-based intervention $\quad 24$

Community-based intervention 26

$\begin{array}{ll}\text { Challenges } & 28\end{array}$

Chapter 4 Intervention effects on the health system 30

$\begin{array}{ll}\text { Availability of abortion services } & 30\end{array}$ 
Provider awareness and perceptions $\quad 34$

Availability of IEC materials $\quad 35$

$\begin{array}{ll}\text { Infrastructure and equipment } & 37\end{array}$

$\begin{array}{ll}\text { Facility and examination room infrastructure } & 37\end{array}$

$\begin{array}{ll}\text { Essential equipment for the provision of abortion services } & 40\end{array}$

$\begin{array}{ll}\text { Abortion-related service delivery } & 40\end{array}$

$\begin{array}{ll}\text { Summary } & 45\end{array}$

Chapter 5 Intervention effects on abortion-related awareness among women 48

$\begin{array}{ll}\text { Abortion-related information: Sources and messages } & 48\end{array}$

Awareness of abortion methods $\quad 51$

Awareness of facilities providing abortion services $\quad 52$

Awareness of legal issues related to abortion $\quad 52$

Summary $\quad 55$

Chapter 6 Experiences of women who underwent abortion 56

Prevalence of abortion: Lifetime and recent

Abortion-related experiences $\quad 56$

Experiences of second trimester and repeat abortions $\quad 57$

Summary $\quad 59$

\begin{tabular}{ll} 
Chapter 7 Summary and conclusions & 60 \\
\hline
\end{tabular}

$\begin{array}{ll}\text { Summary } & 60\end{array}$

Facility-level effects $\quad 61$

Community-level effects $\quad 62$

Limitations

$\begin{array}{ll}\text { Recommendations } & 64\end{array}$

Targeting the most-at-risk $\quad 64$

Shifting preferences for abortion services to the public sector $\quad 64$

Extending interventions to the private sector $\quad 65$

From access to quality services

Integration of facility- and community-based components $\quad 65$

References $\quad 66$ 


\section{List of tables}

Table $1.1 \quad$ Socio-demographic characteristics of study districts, 2000s

Table $1.2 \quad$ Coverage of the study

Table 2.1 Reproductive and child health services provided by PHCs and CHCs, Tonk and Bundi districts, Rajasthan 11

Table 2.2 Abortion services provided by CHCs, Tonk and Bundi districts, Rajasthan 11

Table 2.3 Provider availability at PHCs and CHCs, Tonk and Bundi districts, Rajasthan 12

Table 2.4 Provider awareness of grounds for abortion under the MTP Act and perceptions $\begin{array}{ll}\text { about women's abortion-related rights, Tonk and Bundi districts, Rajasthan } & 13\end{array}$

Table 2.5 Availability of basic infrastructure at PHCs and CHCs in Tonk and Bundi districts, Rajasthan

Table 2.6 Availability of basic equipment at PHCs and CHCs, Tonk and Bundi districts, Rajasthan

Table 2.7 Reproductive and child health related IEC materials displayed at PHCs and CHCs, Tonk and Bundi districts, Rajasthan 15

Table 2.8 Characteristics of households, Tonk and Bundi districts, Rajasthan 16

Table 2.9 Socio-demographic profile of respondents, Tonk and Bundi districts, Rajasthan 17

Table 2.10 Awareness and perceptions of respondents about abortion facilities and providers, Tonk and Bundi districts, Rajasthan 19

Table 2.11 Prevalence and experiences of women who underwent abortion, Tonk and Bundi districts, Rajasthan $\quad 21$

Table 3.1 Distribution of PHCs and CHCs under study, Tonk and Bundi districts, Rajasthan 24

Table 4.1 Constellation of services provided at PHCs and CHCs, Tonk and Bundi districts, Rajasthan

Table 4.2 Availability of trained abortion providers at PHCs and CHCs, Tonk and Bundi districts, Rajasthan

Table 4.3 Awareness among PHC- and CHC-level medical officers about MTP and their perceptions about abortion and women's abortion-related rights, Tonk and Bundi districts, Rajasthan

Table 4.4 Availability of IEC materials in PHCs and CHCs, Tonk and Bundi districts, Rajasthan 
Table 4.5 Availability of basic infrastructure at PHCs and CHCs, Tonk and Bundi districts, Rajasthan

Table 4.6 Examination room infrastructure at PHCs and CHCs, Tonk and Bundi districts, Rajasthan

Table 4.7 Availability of functioning essential equipment for the provision of abortion services, PHCs and CHCs, Tonk and Bundi districts, Rajasthan

Table 4.8 PHCs and CHCs providing abortion, Tonk and Bundi districts, Rajasthan

Table 5.1 Effects of the intervention on information received by women on abortion, Tonk and Bundi districts, Rajasthan

Table 5.2 Messages received by women who reported receiving information on abortion in the year preceding the endline interview by source of message, Tonk and Bundi districts, Rajasthan

Table 5.3 Effects of the intervention on women's awareness of abortion methods, Tonk and Bundi districts, Rajasthan

Table 5.4 Percentage of women who were aware of facilities providing abortion, Tonk and Bundi districts, Rajasthan

Table 5.5 Effects of the intervention on misperceptions held by women about the legality of abortion and awareness of at least one situation in which abortion is legal, Tonk and Bundi districts, Rajasthan

Table 6.1 Prevalence of abortion in the three years preceding the interview, Tonk and Bundi districts, Rajasthan

Table 6.2 Percentage of women by facility/individual who conducted the abortion and abortion method used, among women who underwent abortion in the three years preceding the interview, Tonk and Bundi districts, Rajasthan

Table 6.3 Percentage of women reporting multiple and second trimester abortions, among women who underwent abortion in the three years preceding the interview, Tonk and Bundi districts, Rajasthan 


\section{Acknowledgements}

This assessment of a Comprehensive Abortion Care model was conducted by the Population Council on behalf of the Consortium for Safe Abortions in India, comprising Ipas (Coordinating Partner), Action Research and Training for Health (ARTH), the Centre for Enquiry into Health and Allied Themes (CEHAT), the Family Planning Association of India (FPAI), the Federation of Obstetric and Gynaecological Societies of

India (FOGSI), International Maternal and Child Health (IMCH)-Uppsala University, the Population Council and the Society of Midwives, India (SOMI).

Members of the Consortium have played a key role in the design of the assessment, and have given key inputs at various stages of implementation, analysis and interpretation of findings. This was a cooperative endeavour and their inputs are gratefully acknowledged. We would like to express our appreciation, in particular, to Kalpana Apte, Sangeeta Batra, Koyeli Bhattacharjee, Manju Chugani, Padma Deosthali, Sharad Iyengar, Vinoj Manning, Garima Mathias, M. Prakasamma and Jaydeep Tank.

The Consortium for Safe Abortions in India was generously supported by the Swedish International Development Cooperation Agency (Sida) and the David and Lucile Packard Foundation. Additional support from the Packard Foundation enabled the Consortium to undertake the endline survey. We are grateful to these organisations, and, in particular to Yasmin Zaveri-Roy and Lester Coutinho for their support and insights throughout.

The Department of Medical, Health and Family Welfare, Government of Rajasthan, and district authorities in Tonk and Bundi extended valuable support to both the intervention and its assessment, and we are extremely grateful to Dr. M. L. Jain, Director, RCH; Dr. R. P. Meena, Chief Medical and Health Officer (CMHO), Tonk; Ms. Anuradha Aswal, State Training Coordinator; Dr. Adarsh Bhargava, Professor and Head of Department, Obstetrics and Gynaecology (Retd.), SMS Medical College, Jaipur; and Mr. Hemant Acharya, Consultant IEC, for their partnership at all stages of the project.

An earlier draft of reports in this series was extensively and insightfully reviewed by three luminaries in the field of reproductive health: Kurus Coyaji, Iqbal Shah and Leela Visaria. Their thoughtful and provocative comments are much appreciated and have been incorporated into and, thereby, strengthened this report.

We would also like to acknowledge the cooperation of our Family Planning Association of India partners, and in particular, Kalpana Apte, Koyeli Bhattacharjee and S. P. Singh, who helped us both better understand the intervention and better interpret study findings. Jyoti Moodbidri did an excellent job of editing the report, and our report has benefitted greatly from her many suggestions and her careful attention to detail. We would also like to acknowledge with thanks the huge contributions of Komal Saxena, who managed the publication 
of this report and of MA Jose, who has ably managed the administrative aspects of this study over the last four years. Thanks are due to our team of investigators for their painstaking efforts in collecting data on a topic as sensitive as abortion. Finally, we would like to thank all the women who participated in the study and shared their experiences and insights so willingly. We hope that this report will contribute in some small way to enhancing access to safe abortion services, especially among poor women. 


\section{CHAPTER 1}

\section{Introduction}

\section{Context}

For more than thirty years, following the enactment of the Medical Termination of Pregnancy (MTP) Act of 1971, women in India have been entitled to legal abortion services in registered facilities and by certified providers (Government of India, 1971). Women have the right to access abortions across a range of situations: when the mother's life is at risk or when her physical or mental health is compromised; in case of rape; if the pregnancy is likely to result in the birth of a child with physical or mental abnormalities; and if the pregnancy is the result of contraceptive failure. Additionally, abortions may be performed up to 20 weeks of gestation and the consent of the husband or guardian is not required for adult women. With these liberal conditions, the MTP Act was intended to reduce the incidence of illegal and unsafe abortions. However, most women continue to obtain abortion services outside of registered settings, and/or from uncertified and often unqualified providers. It is estimated that most of the estimated 6.7 million abortions that are performed in India each year are illegal (Chhabra and Nuna, 1994). Moreover, abortions performed by uncertified providers are estimated to be two to 10 times higher than those performed legally by physicians (Ganatra, 2000), and hold potentially serious adverse consequences for women's health. Indeed, complications arising from abortion contribute to some 8 percent of maternal deaths (Office of the Registrar General, India, 2006).

Women's access to safe abortion services from public sector facilities is limited by a range of health system and community-level factors. At the level of the health system, abortion services are rarely available at the Primary Health Centre (PHC) level or in rural areas; most PHCs and even some Community Health Centres (CHCs) lack trained staff and the required equipment and supplies for providing safe abortions (Barge et al., 1998; 2004; Duggal and Barge, 2004; Kalyanwala, Zavier and Jejeebhoy, 2010), or do not have the necessary certification. At the community level, a number of individual- and community-level factors inhibit women from seeking abortion in public sector facilities (see, for example, Elul et al., 2004; Ganatra et al., 2008; Malhotra et al., 2003). These include limited understanding of the legality of abortion, reluctance to obtain services from clinics known to provide abortion services, lack of awareness about the need to seek abortion early in pregnancy, poor perceived quality of care, lack of confidentiality and the frequent insistence on concurrent family planning (Barua and Apte, 2007; Elul et al., 2004; Ganatra, 2000). Indeed, significant numbers of women-one-fifth in a study in Rajasthan-used a home remedy or obtained services from an informal provider in an attempt to terminate their pregnancy; most of these were unsuccessful, leading women to seek services eventually-often in the second trimester-from the formal sector (Elul et al., 2004).

\section{Study objectives}

Recognising the urgent need to enable rural women to acquire accessible and high quality abortion services, a number of organisations-Ipas (Coordinating Partner), Action Research and Training 
for Health (ARTH), the Centre for Enquiry into Health and Allied Themes (CEHAT), the Family Planning Association of India (FPAI), the Federation of Obstetric and Gynaecological Societies of India (FOGSI), International Maternal and Child Health (IMCH)-Uppsala University, the Population Council and the Society of Midwives, India (SOMI) - came together to form the Consortium for Safe Abortions in India. The goal of the Consortium is to increase access to legal, safe, and comprehensive abortion services, including post-abortion family planning, in the public health system, especially among the rural poor. One of its key activities was to develop a comprehensive and evidence-based abortion care model suitable for rural women in different settings. The model, which aimed at addressing both facilitybased and community-based barriers, focused on enabling public sector sites to offer comprehensive abortion care services and simultaneously, to build awareness at woman- and community-levels about the legality of abortion and the availability of safe abortion services in the public sector. A more longterm objective was to enhance public sector use of abortion services and empower poor rural women to access safe abortion services, and services that respond to their need for confidential and nonjudgemental care. This Comprehensive Abortion Care (CAC) model was implemented in one district of a more developed state-Aurangabad district, in Maharashtra - and one district of a lesser developed state, namely, Tonk district, in Rajasthan.

This report describes the CAC model implemented in Tonk district, Rajasthan, and examines the extent to which the model did indeed improve (a) the availability and quality of abortion services in public sector facilities, notably PHCs and CHCs; and (b) women's awareness and experiences with regard to abortion services. Specifically, the report assesses the extent to which exposure to the intervention resulted in improving infrastructure (including equipment and supplies) and provider skills (including training, knowledge and understanding of abortion), and women's awareness of and perceptions about abortion. It also sheds light on progress in the achievement of such longer term objectives as a shift to public sector facilities and trained providers, and a reduction in second trimester abortions.

\section{Background}

Efforts at collecting primary data on abortion in India have been largely restricted to women who have sought abortion in clinical settings. There are, in contrast, few population-based studies that focus on abortion. The National Family Health Survey (NFHS-2) (IIPS and ORC Macro, 2000) did ask questions on abortion and the questions focused on inter-birth intervals. Findings suggest considerable under-reporting: just $2 \%$ reported an abortion over the course of their married life (IIPS and ORC Macro, 2000). However, three notable studies conducted over the last decade, using more detailed probing, have shed light on the prevalence of abortion and the experiences of women who underwent abortion (Elul et al., 2004; Ganatra et al., 2008; Malhotra et al., 2003). Findings indicate considerable variation in the proportions of women who had ever experienced an abortion: for example, 13\% of women aged 15-44 in Alwar district, Rajasthan, had experienced one or more 
abortions over the course of their life (Elul et al., 2004) compared to almost one-fourth of those aged 15-39 in six districts of Madhya Pradesh (Malhotra et al., 2003). The case finding approach used in the Maharashtra study among women in three western districts estimated, moreover, an annual induced abortion rate of 15\% (Ganatra et al., 2008). Abortion ratios-the number of abortions per 100 live births-also varied, ranging from about five for every 100 live births in Madhya Pradesh and Rajasthan to more than twice that (11-14, depending on the methodology employed) in Maharashtra.

These studies also document women's knowledge of the legality of abortion, awareness and practice of sex-selective abortion, providers from whom women sought their abortion, and the post-abortion complications they experienced. They confirm that while knowledge of the legality of abortion was limited, most women were aware of sex-selective abortion. For example, three-quarters of women in the Rajasthan study knew that foetal sex could be determined and a similar proportion knew someone who had undergone a sex-selective abortion. However, 3\% of women who underwent abortion in the Rajasthan and Madhya Pradesh studies compared to $17 \%$ of those in the Maharashtra study, reported sex-selection as a reason for their abortion.

Variation was also observed in the percentage of women who obtained services from outside the formal sector. For example, $20 \%$ of the women who had sought an abortion in the five years preceding the interview in the Rajasthan study reportedly used a home remedy or the services of an informal provider (Elul et al., 2004) while half of the rural women in the Madhya Pradesh study, reported an abortion using "dubious and potentially dangerous means" (Malhotra et al., 2003). In Maharashtra, $45 \%$ of all abortions were carried out by providers who were either not legally recognised as MTP service providers or performed in a place not legally approved for abortion; most were conducted by allopathic physicians not certified to provide abortion, and just $2 \%$ and $12 \%$ were conducted by traditional practitioners and those trained in nonallopathic systems of medicine, respectively.

Post-abortion morbidity was reported by large proportions of women: $68 \%$ in the Maharashtra study, 54\% in the Madhya Pradesh study and 26\% in the Rajasthan study.

In general, in India, few public sector health facilities provide abortion services, and leading obstacles that prevent women's access to these services include a lack of trained providers, appropriate infrastructure or necessary equipment and supplies (Barge et al., 1998; 2004; Duggal and Barge, 2004; Kalyanwala, Zavier and Jejeebhoy, 2010). Many of those that provide abortion services, moreover, continue to use Dilation and Curettage $(\mathrm{D} \& \mathrm{C})$ for first trimester abortions (Barge et al., 2004), a method internationally recognised as inappropriate in general, and only to be used when Manual Vacuum Aspiration (MVA) or medical methods of abortion are unavailable (World Health Organization, 2003).

There have been concerted efforts by the Government of India to increase access to safe abortion services at the PHCs. As early as 2000, the National Population Policy (NPP) (Ministry of Health and Family Welfare, 2000) noted the 
provision of safe abortion services as an important strategy for reducing maternal deaths. Recognising the need to increase access to safe abortion, particularly in rural areas, the Policy recommended expanding the provision of abortion services to the PHC level. Notably, in an attempt to expand the provider base for services in general, the National Rural Health Mission, 2005, added a new cadre of service providers, including doctors trained in the Ayurveda and Homoeopathy branches of medicine (Ministry of Health and Family Welfare, 2005). Also notably, the rules and regulations governing the MTP Act were amended in May 2003 to specify that Medical Abortion (MA) could be provided by certified providers in unregistered facilities, as long as they had access to a registered facility for back-up (Government of India, 2003); as a result, medical abortion can now be provided at the PHC level, provided that back-up surgical support at a higher facility is readily available for referral. Furthermore, the Ministry of Health and Family Welfare has specific strategies to increase access to safe abortion services both at the community and facility levels. At the community level, strategies include spreading awareness on issues related to safe abortion services. At the provider level, training of Auxiliary Nurse Midwives (ANMs) and Accredited Social Health Activists (ASHAs) to provide confidential counselling is advocated; ANMs, ASHAs and Anganwadi Workers (AWWs) are expected to counsel and refer women as well as provide post-abortion care. At the facility level, the aim is to ensure the availability of quality MVA technologies at all CHCs and First Referral Units (FRUs), and at least half of all 24/7 PHCs, and to encourage the provision of quality
MTP services by the private and NGO sectors (Ministry of Health and Family Welfare, 2010). Guidelines to provide MVA up to eight weeks of gestation at the PHC level have been prepared, thus further paving the way for increased access to safe abortion services nationwide (Ministry of Health and Family Welfare, 2001).

\section{Setting}

Tonk district was selected purposively as the intervention district because of the previous engagement of the Family Planning Association of India (FPAI), the Consortium's implementation partner, in this district. Nevertheless, the district was not atypical of Rajasthan, in terms of sociodemographic characteristics, as shown in Table 1.1. The control district, Bundi, was matched on the basis of literacy and economic activity profiles. As evident from Table 1.1, the socio-demographic characteristics of the intervention and control districts are similar.

In Rajasthan, Tonk accounted for about 2.1\% and Bundi $1.7 \%$ of the state's total population of 56.5 million as of 2001 (Office of the Registrar General and Census Commissioner, 2004). Gender differences are quite stark in both districts—-for example, literacy rates ranged from $32-38 \%$ among females to $71-72 \%$ among males and work participation rates from $47-50 \%$ among females to $61-66 \%$ among males. While the level of modern contraceptive use was somewhat higher and that of unmet need for contraception was considerably lower in Tonk than in Bundi, the percentage of women reporting institutional deliveries and deliveries by 


\section{Table 1.1}

Socio-demographic characteristics of study districts, 2000s

\begin{tabular}{|c|c|c|c|}
\hline & Tonk & Bundi & Rajasthan \\
\hline Total population ${ }^{1}$ & $1,211,671$ & 962,620 & $56,507,188$ \\
\hline Sex ratio $(M / F)^{1}$ & 934 & 907 & 921 \\
\hline Juvenile sex ratio $(\mathrm{M} / \mathrm{F})^{1}$ & 927 & 912 & 909 \\
\hline Male literacy $(\%)^{1,2}$ & 70.5 & 71.7 & 75.7 \\
\hline Female literacy $(\%)^{1,2}$ & 32.2 & 37.8 & 43.9 \\
\hline Male work participation $(\%)^{1,2}$ & 60.5 & 65.7 & 61.6 \\
\hline Female work participation $(\%)^{1,2}$ & 46.9 & 49.5 & 41.2 \\
\hline Urban $(\%)^{1}$ & 20.9 & 18.7 & 23.4 \\
\hline Modern contraceptive use $(\%)^{3}$ & 44.3 & 38.7 & 42.3 \\
\hline Unmet need for contraception $(\%)^{3}$ & 14.6 & 24.1 & 21.8 \\
\hline $\begin{array}{l}\text { Mothers who had at least three antenatal check-ups for the } \\
\text { last birth }(\%)^{3}\end{array}$ & 3.1 & 6.1 & 5.0 \\
\hline Institutional deliveries $(\%)^{3}$ & 25.8 & 36.2 & 31.4 \\
\hline Skilled attendance at delivery $(\%)^{3}$ & 41.6 & 48.2 & 44.4 \\
\hline
\end{tabular}

${ }^{1}$ Office of the Registrar General and Census Commissioner (2004).

${ }^{2}$ Ages 7 and above.

${ }^{3}$ International Institute for Population Sciences (2006).

skilled birth attendants was higher in Bundi than in Tonk. Neither district contained a medical college or any other facility for training service providers; District Hospitals were not equipped to provide MTP training.

The intervention (described in detail in Chapter 3) was implemented in Tonk district in general. However, on the basis of their greater readiness to conduct abortions, availability of basic infrastructure and the array of services provided, as recorded in the baseline assessment, 25 of the 45 PHCs and five of the seven CHCs, were selected for special attention (for more details, see Kalyanwala, Zavier and Jejeebhoy, 2010), and community awareness-building activities were conducted in the areas served by these selected PHCs.

\section{Study design and samples}

A quasi-experimental research design, with crosssectional surveys undertaken in control and intervention districts prior to the implementation of the CAC model intervention (baseline) and at its conclusion (endline), was used to evaluate the effects of intervention activities. The baseline investigation was conducted during August-November 2007; the endline during August-October 2010. Two surveys were conducted: at health facility and at community levels among married women aged 15-39-those most likely to have experienced a recent pregnancyat both base- and end-line. 
Facility surveys were conducted in all PHCs and CHCs, but not in the District Hospitals, of Tonk and Bundi. During the facility-based survey phase, we thus covered all of the 80 facilities in the two districts at baseline (45 PHCs and seven $\mathrm{CHCs}$ in Tonk, and 24 PHCs and four CHCs in Bundi), and all of the 83 facilities in the two districts at endline (45 PHCs and seven CHCs in Tonk, and 25 PHCs and six CHCs in Bundi).

Sites for the community-based survey were selected purposively from among the areas served by the facilities selected for intervention in Tonk, and a correspondingly identified set of areas in the control site, Bundi. At the time of the endline survey, indepth interviews were also conducted with women who had undergone abortion in the five years prior to the interview in order to probe their experiences in greater detail than in the baseline survey.

Within each selected PHC area, communitybased surveys of currently married women aged 15-39 were conducted in a sample of villages served by the facilities selected for intervention in Tonk and a similarly situated set of villages in Bundi, at both baseline and endline. The required sample size was determined as 1,000 per district for the baseline survey, based on a presumed lifetime incidence of abortion of $10 \%$, drawing from previous studies (for details of the selection procedures, see Jejeebhoy, Zavier and Kalyanwala, 2010). We reduced the required sample size for the endline survey to 850 per district, based on the actual lifetime incidence of abortion obtained from the baseline survey $(11.1 \%)$, which was higher than the rate adopted for the baseline survey. Correspondingly, a total of 40 and 28 Primary Sample Units (PSUs) or villages were selected for interview from each district at the time of the baseline and endline surveys, respectively, and an average of 23 and 33 women, respectively, were interviewed from each selected PSU. PSUs and respondents within each PSU were drawn independently at the two points in time; the probability that any woman was included in both baseline and endline surveys is remote.

The 2001 Census list of villages served as the sampling frame for the selection of villages. At the first level of stratification, each district was stratified into blocks and the number of villages to be selected from each block was determined according to the share of the population of that block to that of the district. In each block, villages were further stratified by size and the percentage of the populations belonging to scheduled castes or scheduled tribes. The last level of stratification consisted of an order of villages within each stratum by level of female literacy, ordered alternatively in increasing and decreasing levels of female literacy obtained from the 2001 Census (Office of the Registrar General and Census Commissioner, 2004). Villages were then selected systematically from this stratified list, with selection probability proportional to size (PPS).

A complete mapping and household listing operation was carried out in each selected PSU or in selected segments or linked villages as appropriate (large villages were segmented into approximately 150 households and two segments were selected randomly). The list of households provided the necessary frame for selecting households at the second stage. In each PSU, the households to be 
interviewed were selected by systematic sampling. The sampling design was intended to ensure a selfweighting design at the district level. All eligible women in the selected household were selected for interview and no replacement was permitted.

\section{Instruments}

The facility study instrument comprised three components: questions relating to the facility itself, its staffing pattern, types of services provided with a particular focus on abortion-related services and training, and quality of facilities; a facility-level checklist that assessed health centre infrastructure and availability of essential equipment and supplies; and a component on provider awareness about abortion-related issues.

The community-based survey instruments drew on those used in previous studies, notably those by Elul et al. (2004) and Malhotra et al. (2003) discussed above. Two structured instruments - a household questionnaire and a woman's questionnaire-were used to collect data in a face-to-face interview. The household questionnaire was designed to gather demographic information about all permanent household members, as well as information on household socio-economic status. It was also used to identify currently married women aged 15-39 who would be eligible for the individual interview.

The woman's questionnaire included the background information of female respondents as well as their reproductive and abortion experiences, knowledge of abortion legislation and available methods of abortion, and key issues in selecting an abortion provider or facility. Abortion experiences covered the method of abortion experienced (surgical, medical or other methods, including locally available abortion-inducing preparations), complications experienced and quality of care received. Information on women's reproductive experiences was obtained using (a) a detailed birth history, and (b) a detailed history of reproductive events experienced in the five years prior to the interview by way of a calendar that provided monthwise data on women's pregnancy status, contraceptive practice, abortions, stillbirths and miscarriages. At the time of the endline survey, an identical set of questions was posed, with the addition of questions relating specifically to the intervention in order to gauge women's direct exposure to the intervention. In addition, 25 women from Tonk who had experienced an abortion in the five years preceding the endline interview were interviewed in-depth about their experience, including with regard to access to abortion services, quality of care and postabortion contraception (not presented in this report).

Study instruments were prepared in English and translated into Hindi. They were pre-tested and modified suitably, prior to use.

At the time of the baseline survey, interviews were conducted using paper questionnaires, survey data were entered in CSPro 4.0. At the time of the endline survey, interviewers recorded women's responses directly on to mini laptop computers, using a data entry package prepared using CSPro, thus ensuring built-in consistency checks and rapid transmission of data from the field to the Council office. All data were analysed using SPSS-11.0. 
Findings of the facility-based survey are presented by way of means and percentages (PHCs) and absolute numbers (CHCs). Findings of the community-based survey are reported by way of means, medians, percentages and odds ratios.

\section{Analysis}

Descriptive data are presented that compare changes observed over time in Tonk, the intervention site, and Bundi, the control site, in terms of facility preparedness to provide abortion, women's awareness of abortion-related matters, and the experiences of women who underwent abortion in the three years prior to the baseline and endline investigations. The significance of changes between baseline and endline in both districts was tested using t-tests. In addition, in order to assess the effect of the intervention programme on women's abortion-related awareness and practices, logistic regression techniques using Difference-in-Difference (DiD) models were employed. The DiD method (Ashenfelter, 1978; Ashenfelter and Card, 1985) is a statistical method that contrasts the difference in average outcome in the intervention group before and after exposure to the intervention, with the difference in average outcome in the control group at baseline and endline, after controlling for a host of socio-demographic factors. Thus, the DiD method enables us to compare changes that have taken place in the intervention site following programme implementation with those that have occurred in the control site during the same period.

\section{Response rates}

Table 1.2 provides the response rates for household and individual interviews. In the baseline survey, a total of 2,428 households (1,144 and 1,284 in Tonk and Bundi, respectively), yielding a total of 2,049 eligible women (979 and 1,070 in the two districts, respectively), were approached to participate in the study. Similarly, at the endline, 2,599 households (1,295 and 1,304 in the two districts, respectively), and a total of 2,050 eligible women (1,044 and 1,006 in the two districts, respectively), were so approached. Household response rates at the time of the baseline and endline surveys ranged from

\section{Table 1.2}

\section{Coverage of the study}

\begin{tabular}{|l|r|r|r|r|}
\hline & \multicolumn{3}{|c|}{ Baseline } & \multicolumn{2}{|c|}{ Endline } \\
\cline { 2 - 5 } & Tonk & Bundi & Tonk & Bundi \\
\hline Number of villages selected & 40 & 40 & 28 & 1,304 \\
\hline Number of households selected & 1,144 & 1,284 & 1,295 & 93.9 \\
\hline $\begin{array}{l}\text { Household response rate } \\
\text { Number of currently married women }\end{array}$ & 96.3 & 96.0 & 94.6 & 1,006 \\
$\quad$ aged 15-39 identified & 979 & 1,070 & 1,044 & 91.9 \\
\hline Response rate for eligible women & 96.0 & 94.7 & 88.3 & 9 \\
\hline
\end{tabular}


94-96\%; response rates for eligible women fell slightly, from $95-96 \%$ at the time of the baseline survey to $88-92 \%$ at the time of the endline survey.

\section{Structure of this report}

The report contains seven chapters. Chapter 2, drawing on data from the baseline surveys, describes the facility situation as well as the profile of women interviewed in the community-based survey, including their socio-demographic characteristics, their awareness and perceptions of abortion, the prevalence of abortion and experiences of those who had undergone abortion, in the two districts. Chapter 3 briefly describes the Comprehensive Abortion Care model implemented in Tonk and the key components of the intervention, including women's exposure to abortion-related messages. Chapter 4 examines the extent to which the intervention resulted in improved availability of services and the readiness of facilities to provide abortion in Tonk as compared with Bundi. Chapter 5 assesses the effect of the intervention on women's awareness of abortionrelated matters, and Chapter 6 describes the prevalence of abortion at the time of baseline and endline interviews, and the experiences of women who underwent abortion in the three years preceding the interview. Chapter 7 summarises the findings of this study and offers programmatic recommendations to ensure greater access to safe abortion among rural women in the state. 


\section{CHAPTER 2}

\section{Characteristics of health facilities and social and demographic profiles of households and respondents}

In this chapter, we draw on data from the baseline investigation and set the context in which intervention activities were implemented. It presents an overview of the basic infrastructure, constellation of services provided, and availability of abortion services. It also discusses the socio-demographic profiles of study households and individual respondents, the awareness and perceptions of respondents regarding abortion, abortion prevalence, and the experiences of women who had undergone abortion. Findings of the community-based surveyall means, medians and percentages - have been weighted using normalised weights for the total population. However, in order to show the total number of women interviewed, unweighted numbers of respondents (Ns) are provided in each table. Because numbers are unweighted and percentages are weighted, we caution readers against deriving numbers based on the percentages provided in the tables.

\section{Health facilities}

In total, in the two districts, there were $69 \mathrm{PHCs}$ and 11 CHCs: 45 and 24 PHCs, and seven and four CHCs, respectively, in Tonk and Bundi, at the time of the baseline survey. As Table 2.1 shows, while all facilities provided a range of reproductive health services, abortion services were rarely provided. For example, all $\mathrm{PHCs}$ and $\mathrm{CHCs}$ provided antenatal and postpartum services and contraceptive services, and all CHCs and most PHCs (80-87\%), respectively, provided delivery services and conducted tubal ligation. In contrast, abortion services were not provided at any of the 69 PHCs, and just seven of the $11 \mathrm{CHCs}$ were providing abortion at the time of the baseline interview. In addition, two (3\%) PHCs reported that abortion services were provided in the past but had been discontinued.

Among the seven $\mathrm{CHCs}$ providing abortion services at the time of the interview, moreover, most conducted relatively few procedures (Table 2.2). Indeed, just two of the seven CHCs providing abortion had conducted 100 or more abortions in the 12 months preceding the interview and one more had conducted between 51 and 99 abortions. None of the seven CHCs provided second trimester abortions. Notably, five of the seven CHCs reported that abortions were provided three or more days a week or on demand, and all seven provided postabortion contraception. Legal provisions of the MTP Act were not always observed. Although all the seven $\mathrm{CHCs}$ had written guidelines available at the facility, only five maintained an MTP register. Almost all facilities (six of the seven CHCs) continued to require the husband's written consent and not all provided abortion to minors and the unmarried (four and five, respectively, of the seven CHCs). 


\section{Table 2.1}

Reproductive and child health services provided by PHCs and CHCs, Tonk and Bundi districts, Rajasthan

\begin{tabular}{|l|r|c|}
\hline Number of facilities & PHCs (\%) & CHCs (n) \\
\hline ANC and postpartum services & $\mathbf{6 9}$ & $\mathbf{1 1}$ \\
\hline Delivery services & 100.0 & 11 \\
\hline Provision of contraception & 87.0 & 11 \\
$\quad$ Non-terminal methods (condom, oral contraceptive, IUD) & 100.0 & 11 \\
Tubal ligation & 100.0 & 11 \\
$\quad$ Vasectomy & 79.7 & 11 \\
\hline Abortion services currently available ${ }^{1}$ & 68.1 & 11 \\
\hline Abortion services not currently available ${ }^{1}$, but provided earlier & 0.0 & 7 \\
\hline Provided in the three & 2.9 & 0 \\
\hline
\end{tabular}

${ }^{1}$ Provided in the three months preceding the interview.

\section{Table 2.2}

Abortion services provided by CHCs, Tonk and Bundi districts, Rajasthan

\begin{tabular}{|l|c|}
\hline Facilities currently providing abortion services & CHCs (n) \\
\hline $\begin{array}{l}\text { Number of facilities } \\
\text { Number of abortions conducted (12 months preceding the interview) }{ }^{1}:\end{array}$ & 7 \\
\hline 50 or less & 4 \\
\hline $51-99$ & 1 \\
\hline 100 or more & 2 \\
\hline Provide second trimester abortion & 0 \\
\hline Provide abortion services $>2$ days a week or on demand & 5 \\
\hline $\begin{array}{l}\text { Provide post-abortion contraception } \\
\text { Written guidelines available at facility }\end{array}$ & 7 \\
\hline $\begin{array}{l}\text { Maintain MTP register } \\
\text { Abortion provided to minors }\end{array}$ & 7 \\
\hline Abortion provided to the unmarried & 5 \\
\hline Husband's signature mandatory & 4 \\
\hline
\end{tabular}

${ }^{1}$ Estimated for 5 CHCs; obtained from registers in 2 CHCs. 
Table 2.3 presents data on the availability of trained doctors and the sex composition of medical officers and highlights that staffing patterns may indeed pose a major obstacle to women's access to safe abortion services. Findings suggest that while almost every PHC had at least one medical officer, fewer than $5 \%$ had at least one medical officer who was certified to provide MTP services. At the CHC level, while eight of the 11 facilities had at least four medical officers, an abortion-certified provider was available only in the seven facilities providing abortion at the time of the baseline survey. In addition, many facilities were staffed by male doctors only-an enormous socio-cultural barrier inhibiting the acceptability of abortion at public health facilities: indeed, just $20 \%$ of the PHCs had one female doctor, and even at the CHC level, just seven of the 11 facilities so reported. Nursing staff were more widely available, with an average of three and seven nursing staff available per PHC and $\mathrm{CHC}$, respectively.

Provider awareness levels about new techniques of abortion on the one hand and stipulations of the MTP Act and women's abortion-related rights on the other were assessed among at least one medical officer in all the CHCs; in the case of PHCs, however, providers based at just 40 of the 69 facilities responded to questions relating to awareness of abortion issues. Findings, presented in Table 2.4, indicate high levels of awareness about MTP: all the providers were aware, for example, that MA is only prescribed for termination of pregnancy up to seven weeks in India, and $83-85 \%$ of responding medical officers at the PHC level, and 10 medical officers at the CHC level were aware that only MTP-certified providers are legally permitted to provide medical abortion and that the opinion of more than one registered doctor is required for second trimester

Table 2.3

Provider availability at PHCs and CHCs, Tonk and Bundi districts, Rajasthan

\begin{tabular}{|c|c|c|}
\hline & PHCs $(\%)$ & CHCs (n) \\
\hline Number of facilities & 69 & 11 \\
\hline \multicolumn{3}{|l|}{ Availability of doctors at each facility } \\
\hline At least one medical officer (PHC), 4 medical officers $(\mathrm{CHC})^{1}$ & 89.9 & 8 \\
\hline Mean number of doctors & 0.9 & 5.4 \\
\hline Facilities with at least one female doctor & 20.3 & 7 \\
\hline Facilities with at least one certified MTP provider $^{2}$ & 4.4 & 7 \\
\hline \multicolumn{3}{|l|}{ Availability of nursing staff } \\
\hline Facilities with at least 4 (PHC) and 9 (CHC) nursing staff ${ }^{3}$ & 90.9 & 3 \\
\hline Mean number of nursing staff per PHC & 2.6 & 7.0 \\
\hline
\end{tabular}




\section{Table 2.4}

Provider awareness of grounds for abortion under the MTP Act and perceptions about women's abortionrelated rights, Tonk and Bundi districts, Rajasthan

\begin{tabular}{|c|c|c|}
\hline & PHCs (\%) & CHCs (n) \\
\hline Number of facilities & $40^{1}$ & 11 \\
\hline \multicolumn{3}{|l|}{ Awareness of grounds for legal abortion } \\
\hline MA is only prescribed for early abortion & 100.0 & 11 \\
\hline Only MTP-certified MBBS doctors are permitted to prescribe MA & 82.5 & 10 \\
\hline $\begin{array}{l}\text { The opinion of more than one registered doctor is required for } \\
\text { abortions performed at } 12-20 \text { weeks of pregnancy }\end{array}$ & 85.0 & 10 \\
\hline $\begin{array}{l}\text { Consent of husband (or guardian) for abortion is not required for } \\
\text { women aged } 18 \text { and above }\end{array}$ & 55.0 & 7 \\
\hline \multicolumn{3}{|l|}{ Perceptions about women's rights: perceive that women should } \\
\hline Undergo counselling privately & 92.5 & 10 \\
\hline $\begin{array}{l}\text { Be fully informed about the specifics of the medical procedure she is } \\
\text { to undergo }\end{array}$ & 85.0 & 10 \\
\hline
\end{tabular}

${ }^{1}$ Doctors were not available in 29 facilities.

abortions. Fewer providers- $55 \%$ and seven, respectively-were aware that the consent of the husband or guardian is not required for women aged 18 and older. The majority, moreover, perceived that women should obtain confidential counselling and should be fully informed about the specifics of the procedure they were to undergo $(85-93 \%$ and 10 , respectively).

Another fundamental factor inhibiting the readiness of facilities to provide abortion services relates to lack of appropriate infrastructure. Findings, presented in Table 2.5, reiterate that even the basic infrastructure required for providing health care services, in general, remains inadequate. For example, just three in five PHCs contained the four beds considered a minimum requirement for PHCs, one in five did not have electricity facilities, and just over half had regular access to transport facilities in case of an emergency. While infrastructure was considerably better at the $\mathrm{CHC}$ level, just eight of the $11 \mathrm{CHCs}$ contained 30 beds, the minimum requirement for $\mathrm{CHCs}$ in general, and just nine had regular access to transport facilities in case of an emergency. Moreover, just 7\% of all PHCs and two of the $11 \mathrm{CHCs}$ contained all four facilities (minimum number of beds, electricity, piped water and regular transport facility) suggesting the availability of basic infrastructure. Examination room infrastructure was also limited: just 3\% of all PHCs and seven of the $11 \mathrm{CHCs}$ contained a separate examination room, visual privacy, an operating table with stirrups and a wash basin with running water.

Also inhibiting readiness to provide abortion services is the lack or uneven distribution of the necessary equipment for providing abortion services. As Table 2.6 shows, although abortion-related 


\section{Table 2.5}

Availability of basic infrastructure at PHCs and CHCs in Tonk and Bundi districts, Rajasthan

\begin{tabular}{|c|c|c|}
\hline & PHCs (\%) & CHCs (n) \\
\hline Number of facilities & 69 & 11 \\
\hline \multicolumn{3}{|l|}{ Beds available } \\
\hline Average number of beds & 4.3 & 32.4 \\
\hline At least 4 (PHC) and $30(\mathrm{CHC})$ beds available & 62.3 & 8 \\
\hline \multicolumn{3}{|l|}{ Electricity available } \\
\hline Electricity connected & 78.3 & 11 \\
\hline \multicolumn{3}{|l|}{ Water supply } \\
\hline Main source of water supply-piped water & 23.2 & 4 \\
\hline \multicolumn{3}{|l|}{ Transport } \\
\hline Transport and fuel regularly available for referral & 55.1 & 9 \\
\hline \multicolumn{3}{|l|}{ General infrastructure } \\
\hline $\begin{array}{l}\text { Facilities with electricity, at least } 4 \text { beds (PHC) and } 30 \text { beds }(\mathrm{CHC}) \text {, } \\
\text { piped water and regular transport facility }\end{array}$ & 7.2 & 2 \\
\hline \multicolumn{3}{|l|}{ Examination room infrastructure } \\
\hline Separate room for examination & 79.7 & 10 \\
\hline Visual privacy & 72.5 & 10 \\
\hline Wash basin with running water & 13.0 & 9 \\
\hline Operating table (with stirrups) & 33.3 & 9 \\
\hline Facilities with all of the above & 2.9 & 7 \\
\hline
\end{tabular}

\section{Table 2.6}

Availability of basic equipment at PHCs and CHCs, Tonk and Bundi districts, Rajasthan

\begin{tabular}{|c|c|c|}
\hline & PHCs (\%) & CHCs (n) \\
\hline Number of facilities & 69 & 11 \\
\hline \multicolumn{3}{|c|}{$\begin{array}{l}\text { Availability of functioning essential equipment for the provision of } \\
\text { abortion services }\end{array}$} \\
\hline MVA or MR syringe & 18.8 & 6 \\
\hline Suction machine (EVA) & 27.5 & 10 \\
\hline EVA or MVA equipment & 33.3 & 11 \\
\hline Tenaculum/Volsellum & 68.1 & 9 \\
\hline Suction cannulae & 27.5 & 9 \\
\hline Set of dilators & 43.5 & 10 \\
\hline \multicolumn{3}{|l|}{ Infection prevention/sterilisation equipment } \\
\hline Autoclave drum & 58.0 & 10 \\
\hline \multicolumn{3}{|l|}{ Facilities with essential equipment } \\
\hline EVA or MVA equipment, volsellum, cannuale and autoclave & 14.5 & 8 \\
\hline
\end{tabular}


equipment was not universally available, it was available in considerably more facilities than those providing abortion at the time of interview. For example, while seven $\mathrm{CHCs}$ were providing abortion at the time of interview, all 11 facilities contained Electric Vacuum Aspiration (EVA) and/or MVA equipment. Likewise, while not a single PHC was providing abortion, as many as one-third had EVA or MVA equipment. Related essential equipment such as suction cannulae and volsellum were also available in most of these facilities. Finally, infection prevention/sterilisation equipment was available in just $58 \%$ of all PHCs and 10 of the 11 CHCs. While individually, equipment was available in a number of facilities, all of the necessary equipment for the provision of EVA or MVA was far from universally available: just 15\% of all PHCs and eight of the $11 \mathrm{CHCs}$ contained all of this equipment.

Yet another deterrent to abortion service readiness was the paucity of abortion-related IEC materials in facilities (Table 2.7). Indeed, more than $90 \%$ of all PHCs and almost all CHCs reported the availability of IEC materials pertaining to child health and family planning; information on abortion-related issues was far less likely to be available. Moreover, what was available tended to focus, at least at the PHC level, on the illegality of sex selection and sex-selective abortion. In contrast, just 3\% of the PHCs and five of the $11 \mathrm{CHCs}$ reported the availability of materials pertaining to the legality and availability of abortion services, or on dispelling the confusion between restrictions on sex-selective abortion and the right to undergo medical termination of pregnancy.

\section{Community survey}

The community-level survey was conducted in a total of 80 villages in the two districts; a total of 2,428 households were reached, and from these households, a total of 2,049 currently married women aged 15-39 were interviewed.

\section{Table 2.7}

Reproductive and child health related IEC materials displayed at PHCs and CHCs, Tonk and Bundi districts, Rajasthan

\begin{tabular}{|l|r|r|}
\hline & PHCs (\%) & CHCs (n) \\
\hline Number of facilities & $\mathbf{6 9}$ & $\mathbf{1 1}$ \\
\hline Child health including immunisation & 92.8 & 9 \\
\hline Maternal health & 72.5 & 10 \\
\hline Family planning (including posters, brochures, samples) & 94.2 & 11 \\
\hline Illegality of sex-selection practices and abortion & 18.8 & 6 \\
\hline Legality, availability of abortion & 2.9 & 5 \\
\hline
\end{tabular}




\section{Characteristics of households}

As evident from Table 2.8, almost all structures in which the respondents resided were self-owned (98\%), and three-fourths of the respondents resided in households owning agricultural land (77\%). The average household size was about five. Household amenities were, however, limited: just $27 \%$ lived in a pucca structure, just $8 \%$ had their own flush toilet, $49 \%$ had electricity, and for just $14 \%$, the main source of drinking water was their own piped water/ hand pump/covered well.

Household economic status was measured using an index composed of household asset data on ownership of selected durable goods as well as data on access to amenities, and ownership of agricultural land; it was adapted from the household standard of living index used in the Youth in India: Situation and Needs study (International Institute for Population Sciences and Population Council, 2010). The index was constructed using a host of amenities and scores ranged from 0 to 53 (for details, see Jejeebhoy, Kalyanwala and Zavier, 2010). The mean score on the standard of living index was 13.4 reflecting a relatively low overall economic status.

\section{Background characteristics of respondents}

Table 2.9 presents the socio-economic characteristics of respondents. On average, respondents were 27 years old, three-quarters had never been to school, just $5 \%$ had completed at least Class 10 , and $59 \%$ had worked in the 12 months preceding the interview. As far as fertility levels are concerned,

\section{Table 2.8}

\section{Characteristics of households, Tonk and Bundi districts, Rajasthan}

\begin{tabular}{|c|c|}
\hline & Households \\
\hline Number of households & 2,334 \\
\hline \multicolumn{2}{|l|}{ Ownership of residence, agricultural land } \\
\hline Residence (\%) & 97.7 \\
\hline Agricultural land (\%) & 77.2 \\
\hline Household size: Mean number of usual household members & 5.4 \\
\hline Type of house: Pucca structure (\%) & 26.6 \\
\hline \multicolumn{2}{|l|}{ Household amenities } \\
\hline Toilet facility: own flush toilet (\%) & 7.5 \\
\hline Source of lighting: electricity (\%) & 49.2 \\
\hline Source of drinking water: own piped water/hand pump/covered well (\%) & 14.0 \\
\hline \multicolumn{2}{|l|}{ Economic status } \\
\hline Standard of living index $(0-53)$, mean score & 13.4 \\
\hline
\end{tabular}

Note: All Ns are unweighted. 


\section{Table 2.9}

Socio-demographic profile of respondents, Tonk and Bundi districts, Rajasthan

Socio-demographic factors

Number of women

Current age (years): Mean

\section{Educational attainment}

Never attended school (\%)

Completed Class 10 or higher (\%)

Mean years of education completed

\section{Working status}

Worked in the last year (\%)

\section{Fertility and child mortality}

Mean number of children ever born

Mean number of surviving children

Experienced at least one child death (\%)

\section{Contraception}

Aware of at least one non-terminal method (\%)

Ever practised contraception (\%)

Practising contraception at the time of interview (\%)

Terminal method

Non-terminal method

Traditional method

\section{Women aged 15-39}

1,953

27.4

74.8

4.9

1.8

59.2

2.5

2.2

22.3

96.5

55.7

50.2

37.4

7.3

5.5

Note: All Ns are unweighted.

on average, women reported about 2.5 and 2.2 live births and surviving children, respectively, and $22 \%$ had experienced one or more child deaths. Contraception awareness was high; awareness of even non-terminal methods was almost universal and $56 \%$ of respondents had ever practised contraception at some point in their life. At the time of the interview, 50\% were practising contraception, with about three-quarters of these women reporting tubal ligation.
Awareness and perceptions of respondents about abortion, facilities and providers

In order to capture the extent to which lack of awareness may pose a barrier to safe abortion, the survey explored women's awareness about abortion and its legal status as well as of facilities in which abortion is provided. Findings, described in Table 2.10, confirm that awareness remains patchy and may well impede women's access to safe abortion. 
Women were asked about their awareness of different methods of abortion, and those who reported awareness of surgical or medical methods were probed about their correct awareness of these methods. Findings show that a significant minority of women had no idea about how abortion is performed (18\%). In addition, fewer women were aware of pills used to induce abortion than of surgical abortion $(64 \%$ versus $73 \%)$. We note that we could not distinguish between awareness of the mifepristone-misoprostol combination and the numerous other oral preparations available to women in the baseline survey, and it is likely that not all women who reported awareness of pills used to induce abortion were referring to the mifepristonemisoprostol combination, but rather to these traditional preparations available in their village or neighbouring villages.

Knowledge of the legality of abortion was also far from universal. While the majority of women $(73 \%)$ were aware of at least one situation in which abortion is legal in India, an equal proportion (72\%) held one or more misconceptions about women's right to obtain abortion. More specifically, almost half of all women believed that abortion is not legally available to unmarried women (47\%) or to those who have experienced contraceptive failure (46\%), and $40 \%$ each believed that abortion is not legally available to women whose health is endangered by the pregnancy or who have a strong chance of foetal malformation. Further, almost all women $(97 \%)$ believed that it is mandatory for women undergoing abortion to have their husband's consent.
Awareness of the location of abortion facilities and providers was also limited. For example, a significant minority of women (19\%) were unaware that abortion services were available at public or private sector facilities in their district, and at the same time, large proportions_-almost halfreported that abortion services were available from providers currently outside the provisions of the Act. Notably, women were far better informed about the availability of abortion in public than private sector facilities: while $80 \%$ of women were aware that abortion is conducted in public sector facilities, just $30 \%$ reported awareness that abortion is conducted in a private sector facility.

Finally, awareness about foetal sex determination and the prevalence of sex-selective abortion was quite widespread. Over four in five women $(84 \%)$ knew that foetal sex can be determined, and among those who knew so, about half knew or had heard of someone who had obtained a sex-selective abortion, and four in five knew where sex-determination tests were performed.

Sources of information-both formal and informal-about abortion were limited. Findings highlight that just one-fifth of respondents (19\%) had obtained information in the year preceding the interview through interpersonal contacts (IPC), group meetings or the media, and almost one quarter $(23 \%)$ had discussed abortion with family or friends in the year preceding the interview.

\section{Prevalence and experiences of abortion}

Data were collected on the experiences of abortion over the course of the woman's lifetime. In addition, 


\section{Table 2.10}

Awareness and perceptions of respondents about abortion facilities and providers, Tonk and Bundi districts, Rajasthan

Awareness of any method of abortion (\%)

\section{Awareness of legality of abortion}

Women correctly aware of (\%)

At least one condition under which abortion is legal (of 6 conditions)

Misperceptions held (\%)

At least one misperception about the conditions under which abortion is legal

Illegal for an unmarried woman to access abortion

Illegal for a woman whose pregnancy results from contraceptive failure (“accidentally")

to access abortion

45.6

Illegal for a woman whose pregnancy has resulted from rape to access abortion

Illegal for a woman whose health is endangered by the pregnancy to access abortion

Even if there is a strong chance of foetal malformation, illegal for a woman to access abortion

Illegal for a woman who is more than 20 weeks pregnant to access abortion

A woman undergoing abortion requires her husband's (or guardian's) consent

Awareness of abortion facilities and providers (\%)

Aware of public or private sector facilities/providers of abortion services

Aware of any private sector facility

Aware of other providers of abortion services

Knowledge of sex-selective abortion (\%)

Aware that it is possible to determine the sex of the foetus

Sources of information about abortion (\%)

Mass media

$\mathrm{IPC}^{3}$ or group meetings

Note: All Ns are unweighted.

${ }^{1}$ Includes the mifepristone-misoprostol combination and any other pills.

${ }^{2}$ Of those who were aware that sex determination is possible $(N=1,635)$.

${ }^{3}$ Includes health care providers. 
using a reproductive life-event calendar, we recorded month-wise information on reproductive events, including abortions experienced over the five years preceding the interview. Findings relating to lifetime experience of abortion as well as abortions experienced during the three years prior to the interview, so as to capture the period during which the intervention was conducted and a comparable period prior to the baseline survey, are summarised in Table 2.11.

Findings show that $11 \%$ of all women interviewed had experienced one or more abortions over their lifetime and $4 \%$ had experienced an abortion in the three years prior to the interview. The abortion ratio ranged from 6 per 100 live births over the course of women's life, to 9 per 100 live births in the three years prior to the interview. These ratios are comparable with those obtained in previous community-based studies of abortion among rural women elsewhere in the country (Elul et al 2004; Ganatra et al., 2008; Malhotra et al., 2003; Saha, Duggal and Mishra, 2004).

Findings also suggest that considerable proportions of women underwent a second trimester abortion, had experienced more than one abortion, had sought pregnancy termination from an unqualified provider and had made more than a single attempt to terminate the last pregnancy. Onethird $(32 \%)$ of all abortion-seekers and one-quarter (25\%) of those who had undergone an abortion in the three years prior to the interview reported that they had done so in their second trimester of pregnancy. Repeat abortions were fairly common: Indeed, 19\% of women who had ever experienced an abortion, and $27 \%$ of those who had undergone an abortion in the three years prior to the interview, had undergone more than one abortion over the course of their life. In addition, a number of women who had ever or recently experienced an abortion$11 \%$ and $13 \%$, respectively — had attempted to induce the abortion themselves or with the help of a family member or friend, or had approached an informal or untrained provider, including nurses/ ANMs and chemists. Successful abortions had been performed, for the most part by doctors; however, $9 \%$ of women who had ever had an abortion and $11 \%$ of those who had experienced an abortion in the three years preceding the interview reported that their pregnancy had been terminated by a nurse/ ANM or traditional practitioner or with medicines supplied by a chemist.

Also evident from Table 2.11 is that the majority of women who had ever or recently experienced an abortion had undergone surgical abortion (85-86\%). In order to probe whether D\&C or MVA had been experienced, we asked whether the woman was given general anaesthesia (suggesting $\mathrm{D} \& \mathrm{C}$ ) or whether the abortion was conducted using a syringe or 'pichkari' (suggesting MVA): findings suggest that the majority had undergone D\&C. In contrast, just 5\% and 9\% of women, respectively, who had ever or recently undergone an abortion reported a medical abortion. In addition, 6-10\% reported that their abortion had been conducted using injections.

Post-abortion contraception was far from universal; for example, just half of the women $(52 \%)$ who had experienced abortion in the three years 
Table 2.11

Prevalence and experiences of women who underwent abortion, Tonk and Bundi districts, Rajasthan

\begin{tabular}{|c|c|c|}
\hline & Lifetime & $\begin{array}{l}\text { During last three } \\
\text { years }\end{array}$ \\
\hline Number of women & 1,953 & 1,953 \\
\hline \multicolumn{3}{|l|}{ Prevalence of abortion } \\
\hline Women experienced abortion (\%) & 11.1 & 3.7 \\
\hline Abortion ratio (number of abortion per 100 live births) & 5.7 & 9.4 \\
\hline Number of women who experienced abortion & 221 & 75 \\
\hline \multicolumn{3}{|l|}{ Experiences $(\%)$} \\
\hline Women reporting second trimester abortions & 31.8 & 25.2 \\
\hline Women reporting multiple abortions & 19.0 & 27.2 \\
\hline Women who sought termination from an untrained individual ${ }^{1}$ & 10.9 & 12.8 \\
\hline \multicolumn{3}{|l|}{ Women whose abortion was conducted by: (\%) } \\
\hline Public sector doctor & 50.9 & 45.2 \\
\hline Private doctor & 40.3 & 43.8 \\
\hline Nurse/ANM, chemist, traditional practitioner & 8.8 & 11.0 \\
\hline \multicolumn{3}{|l|}{ Abortion method used (\%) } \\
\hline Surgical & 84.9 & 85.9 \\
\hline Medical & 5.1 & 8.5 \\
\hline Injections & 9.7 & 5.6 \\
\hline Vaginal herbs/roots/foreign bodies/homemade concoctions & 0.5 & 0.0 \\
\hline Ayurvedic medicines & 0.0 & 0.0 \\
\hline \multicolumn{3}{|l|}{ Post-abortion contraception (\%) } \\
\hline Adopted post-abortion contraception & 35.2 & 52.4 \\
\hline Adopted a permanent method & 11.6 & 9.7 \\
\hline Adopted any modern non-terminal method & 18.0 & 37.5 \\
\hline \multicolumn{3}{|l|}{ Physical access to facilities and providers (\%) } \\
\hline Travelled for more than an hour to reach the facility or provider & 55.3 & 58.0 \\
\hline \multicolumn{3}{|l|}{ Quality of care $(\%)^{2}$} \\
\hline Very satisfied with the provider & 39.9 & 48.5 \\
\hline Would seek abortion services again if needed/recommend to others & 82.5 & 82.4 \\
\hline Provider gave enough time to respondent to explain her problem & 98.3 & 97.1 \\
\hline Provider gave enough privacy to respondent & 88.7 & 84.5 \\
\hline Provider talked about post-abortion contraception & 39.9 & 47.7 \\
\hline Provider did not require husband's consent & 10.5 & 13.4 \\
\hline $\begin{array}{l}\text { Provider or facility did not force the woman to accept } \\
\text { contraception as a condition for abortion }\end{array}$ & 85.6 & 82.4 \\
\hline \multicolumn{3}{|l|}{ Cost incurred for the abortion procedure and provider fees (\%) } \\
\hline No charge & 1.4 & 1.4 \\
\hline$>$ Rs 500 & 70.0 & 76.0 \\
\hline$>$ Rs 1,000 & 48.4 & 56.3 \\
\hline
\end{tabular}

Note: All Ns are unweighted.

${ }^{1}$ Includes themselves, a family member or friend, or an informal or untrained provider, including nurses/ANMs and chemists.

${ }^{2}$ Excludes women who obtained medication directly from a chemist and used it successfully to terminate the pregnancy. 
prior to the interview had adopted contraception following their abortion. Among these women, for the most part, non-terminal methods, including the condom and oral contraceptives were adopted (by $72 \%$ of those who had adopted post-abortion contraception); at the same time, $19 \%$ had adopted female sterilisation. Those who had adopted contraception differed from those who had not in significant ways: they were more likely to have received counselling, to be older, to have at least one surviving son and to come from better-off households (not shown in table).

A number of obstacles appeared to inhibit access to abortion services and the quality of the experience. For example, physical access to facilities and providers was difficult: more than three in five women who had undergone abortion in the three years preceding the survey reported that they had travelled for more than an hour to reach the facility in which their abortion had been conducted.

Second, several concerns persist with regard to quality of care experienced by women. In general, women's experiences were mixed. The large majority-between $82 \%$ and $98 \%$ of those who had ever experienced an abortion or undergone one in the three years prior to the interview-reported that they would return to the same facility if they needed an abortion in the future or would recommend the provider to others, and that they had been given enough time and privacy by the provider. At the same time, just $40-49 \%$ of women who had ever or recently (in the three years preceding the interview) experienced an abortion reported that the experience was very satisfactory. Moreover, a small minority (11-13\%) reported that the provider had not required the consent of their husband, a procedure not required under the Act, and fewer than half of all women-just $40-48 \%$-reported that the provider had counselled them about adopting a method of contraception. Disturbing proportions of women-14-18\%-reported that the provider or facility had forced them to adopt a method of contraception as a condition for providing the abortion. Finally, abortion costs were significant: as many as $70-76 \%$ of women had paid more than Rs 500 and 48-56\% had paid more than Rs 1,000; just $1 \%$ reported that the procedure had been conducted completely free of charge. 


\section{CHAPTER 3}

\section{The Comprehensive Abortion Care model}

The Consortium for Safe Abortions in India, as mentioned earlier, comprises several major players in the abortion field in the country. Its main goal is to increase poor rural women's access to legal, safe and comprehensive abortion services, including post-abortion family planning, in the public health system. With this aim, a district-level model implemented at both health system and community levels was developed and implemented in Tonk district of Rajasthan state by Family Planning Association of India (FPAI), one of the seven members of the Consortium. The model aimed at addressing both health system and community-level barriers to safe abortion, thereby enabling public sector sites to offer comprehensive abortion care services and simultaneously, building awareness among and empowering poor rural women to access safe and good quality abortion services.

This chapter describes the objectives of the intervention, its design, the main components and challenges faced-both at the health system and community levels_-in its implementation.

\section{Objectives}

As mentioned above, the CAC model was twopronged - at facility and community levels. More specifically, at the facility level, the objectives were to facilitate service delivery at public sector sites by enhancing the capacity of PHCs and CHCs, as well as the District Hospital to deliver comprehensive abortion services. Activities at the facility level included the training of abortion providers and other personnel, ensuring the availability of equipment and regular supplies, and regular monitoring of programme activities. At the community level, the model aimed to increase, among women and men, awareness of the legality, safety and availability of abortion services in the community, sensitise communities to the importance of early termination of pregnancy, the dangers of unsafe or late abortion, the availability of newer and safer methods of abortion (MVA/MA) and the location of safe abortion services, especially those in the public sector.

The intervention was implemented in partnership with the Department of Medical, Health and Family Welfare, Government of Rajasthan. Indeed, the state government supported the intervention in conducting a number of the facilitylevel activities, including the training of providers, upgrading the general infrastructure of the selected facilities and provision of equipment at these facilities. Besides, the state government also extended assistance for setting up provider training facilities and deputing trainees, and provided inputs for the final design of the intervention. The Consortium's role was to provide technical support and monitoring of activities and to raise community-level awareness about the legality of abortion and the availability of safe abortion services in the public sector.

As in the case of facility-based activities, the communication strategy, content and materials were developed and produced in partnership with the Department of Medical, Health and Family Welfare, 


\section{Table 3.1}

Distribution of PHCs and CHCs under study, Tonk and Bundi districts, Rajasthan

\begin{tabular}{|l|c|c|c|c|}
\hline & \multicolumn{3}{|c|}{ Tonk } & \multicolumn{2}{c|}{ Bundi } \\
\hline PHCs & Baseline & Endline & Baseline & Endline \\
\hline Intervention & $\mathbf{4 5}$ & $\mathbf{4 5}$ & $\mathbf{2 4}$ & $\mathbf{2 5}$ \\
\hline Non-intervention & 25 & 25 & - & - \\
\hline CHCs & 20 & 20 & - & - \\
\hline Intervention & 7 & 7 & $\mathbf{4}$ & $\mathbf{6}$ \\
\hline Non-intervention & 5 & 5 & - & - \\
\hline
\end{tabular}

Government of Rajasthan, including the state IEC Bureau. Indeed, materials were owned by the Government of Rajasthan and released by the Health Minister, and subsequently distributed among various districts.

\section{Setting}

The intervention in Rajasthan focused on Tonk district. Specifically, facility-level activities were conducted in 30 public sector sites -25 of the 45 PHCs and five of the seven CHCs of the district (Table 3.1). Community-level activities were conducted in the villages served by these sites. Selection of the sites was made by FPAI on the strength of the findings of the baseline facility study; the selection of facilities was made purposively, based on their greater readiness for abortion services as measured by three major criteria-infrastructure availability, current service provision, and availability and willingness of trained providers (for more details, see Kalyanwala, Zavier and Jejeebhoy, 2010).

Bundi, the control site, had 24 PHCs and four $\mathrm{CHCs}$ at the time of the baseline survey. By the time of the endline survey, one additional PHC and two additional CHCs had been created and, as such, there were 25 PHCs and six CHCs; no changes had taken place in Tonk district during the intervention period.

\section{Implementation}

Intervention activities were launched in two phases across the identified public sector facilities and the villages served by these facilities. Activities were conducted at both facility and community levels: facility-level activities were conducted between March 2008 and July 2009, and community-level activities over approximately 12 months, starting in April 2009 and ending in March 2010 (FPAI, personal communication).

\section{Facility-based intervention}

In order to facilitate service delivery at the selected public sector facilities, the intervention focused on building partnerships between the implementing agency and state and district government officials, strengthening facilities, and building a cadre of 
trained abortion providers and other related facilitylevel personnel.

With a view to build ownership of the model, extensive efforts were made, from the early stages of the project, to involve state and district government representatives in the development and implementation of project activities. Meetings were held with key government officials to solicit their support and their inputs in the final design of the intervention project.

In order to strengthen the selected service delivery sites to provide quality services, in partnership with the district authorities, inventories of available and required infrastructure, equipment and supplies were prepared and efforts were made to provide equipment and supplies as required, such as MTP instruments, MVA kits, equipment for infection control measures and so on, and to ensure a regular supply of consumables.

Perhaps the most critical aspect of the model was conducting activities to fill the gap in trained abortion providers and other personnel in PHCs and CHCs. As training facilities did not exist in the district, FPAI, in collaboration with the Department of Medical, Health and Family Welfare, Government of Rajasthan, identified and finalised one hospital in Jaipur-Zanana Hospital—for training abortion service providers, and with the subsequent approval of the Department of Medical, Health and Family Welfare, proceeded to strengthen and upgrade this facility to serve as a training centre. In order to strengthen the skills of staff at this site and create a cadre of master trainers, a first activity was to train trainers. A six-day Training of Trainers (ToT) programme was conducted for four gynaecologists (two each from CHCs and the District Hospital) in March 2008. Training content included techniques of MVA and EVA as well as procedures relating to MA. It also raised awareness among trainees about the MTP Act, abortion as a social justice and reproductive rights issue, and the ways in which gender inequities affect women's access to safe abortion. Finally, it provided information about biosafety and infection prevention.

Manuals and instruction guides developed by Ipas were adapted and used as resource materials for training programmes. These manuals covered all aspects of CAC—clinical aspects as well as such non-clinical components such as quality of care, client rights, gender equity and the importance of non-judgemental attitudes towards abortionseekers, and were made available to both master trainers and trainees. Using these guides, orientation training programmes were held for master trainers to acquaint them with new technologies and skills in providing comprehensive abortion services and to equip them to become trainers. Training programmes were also held for MBBS doctors in order to certify them as providers of abortion services; and for nursing staff to support abortion services and provide relevant non-clinical services. As in the case of master trainers, training also highlighted the importance of quality of care, client rights and gender equity in all interactions with abortionseekers. Training was provided to teams of providers (medical officer and nurse) from various PHCs and CHCs; the Department of Medical, Health and Family Welfare, Government of Rajasthan played a key role in identifying and deputing the 
teams for MTP training. Finally, training was also provided to PHC-, CHC- and District Hospitallevel data entry operators in order to improve the quality of recording and reporting; they were also sensitised to the requirements of the MTP Act, including the reporting requirements under the Act, and encouraged to maintain and submit accurate monthly reports.

Activities were overseen and monitored extensively by FPAI representatives. Inputs included mentoring during training programmes; providing on-site support as well as tracking CAC service delivery at each selected facility with the intention of improving service quality and ensuring the submission of monthly reports.

By the end of the implementation phase, four obstetricians/gynaecologists had been trained as Master Trainers. In addition, $36 \mathrm{MBBS}$ doctors, including 33 from PHCs and three from CHCs, had been trained and certified to provide CAC services, 34 nursing staff had been trained in non-clinical aspects of CAC service delivery, and 30 facilities had been strengthened. In addition, seven block level data entry operators and 28 data assistants had also been trained.

\section{Community-based intervention}

A decision was made to initiate community-level activities only after the completion of facility-based activities; because of delays in fulfilling facilitybased activities - mainly related to establishing a training facility to train abortion providers, the start of community-level implementation was, in turn, delayed. As a result, community-based activities took place for a year, and close engagement with women and other community members, over a five-month period-November 2009 to March 2010.

The community-based intervention took place in broadly two phases. In the first phase, in collaboration with the Department of Medical, Health and Family Welfare, Government of Rajasthan, a communication strategy development consultation was held, leading to the development of a multi-pronged Behaviour Change Communication (BCC) strategy, including BCC/IEC materials to be used at community-level, and tools for fieldlevel workers. Also during this phase, implementing NGO partner organisations were identified, and their field staff members trained in relevant aspects of project implementation. In the second phase, ANMs, AWWs, ASHAs and Panchayati Raj Institution (PRI) members were oriented, and community-based activities were implemented.

The BCC strategy was implemented, at the village level, in six blocks of the district, namely, Deoli, Malpura, Niwai, Piplu, Todarisingh and Uniara, by the five local NGOs under the supervision and guidance of a lead NGO, namely the Rajasthan Voluntary Health Association. Intervention activities targeted women aged 15-49, men aged 18-49 and village-level health workers.

Training of NGO field staff responsible for implementing the communication strategy was conducted over two days. It familiarised NGO field staff with the basic aspects of CAC, sharpened their skills in interpersonal communication and group facilitation, introduced them to the outdoor and interpersonal communication materials developed 
by the project, and trained them in using these tools in the course of BCC activities. Training and orientation of local health care providers such as ANMs, ASHAs and AWWs was conducted, in turn, by the implementing NGOs. In the course of group meetings, ANMs, ASHAs and AWWs were familiarised on issues related to the legality of abortion, unsafe abortion, CAC services including contraception, and to refer women seeking abortion to appropriate safe, certified facilities, They were also provided reference booklets on these topics. Through the project period, a total of 1,841 village-level health care workers were sensitised.

The BCC strategy sought to increase awareness of the legality, safety and availability of abortion services; to increase the use of safe abortion services, particularly in the public sector among women facing an unwanted pregnancy, and to build a positive environment, more generally, on the topic of safe abortion. A range of materials was prepared, including leaflets and information booklets designed specifically for neo-literate women; posters, billboards, and scripts for street plays and a docu-drama (a short film), using local terminology. The scripts highlighted the need for accessing safe abortion services, the dangers of accessing abortion from untrained providers and undergoing second trimester abortion as well as issues related to son preference. All communication materials were pretested and suitably modified prior to their use in the community.

BCC activities ranged from interpersonal communication and group meetings to street plays, docu-dramas, community radio programmes and distribution of easy-to-understand reference materials, and were conducted at various levels. They included group meetings with women's self-help groups as well as orientation programmes for PRI members, who, as key community leaders, were sensitised to the need to support BCC activities in order to facilitate women in the communities to access safe abortion services. Most interactions with the community were interactive and included discussions, stories, games, street plays and so on. The focus of the activities was on enabling communities to better appreciate the dangers of unsafe abortion and the importance of obtaining timely abortions from appropriate facilities; at the same time, they also conveyed information on recognition of symptoms of pregnancy, steps to be taken once the pregnancy is diagnosed and use of contraception.

Street plays and docu-drama shows attracted large numbers of community members, while wall paintings provided information on the legality and availability of safe abortion services, new techniques of abortion (MVA/MA), dangers of unsafe abortion and so on. The wall paintings carried short pertinent messages describing the action to be taken in case of an unwanted pregnancy.

Monitoring data from FPAI indicate that in total, 617 wall paintings were displayed, 104 street plays were conducted and docu-drama shows were held at 126 locations. In addition, ten community radio programmes on safe and legal abortion were prepared and aired, including talks by experts, discussions, folk songs and phone-in conversations. In addition, several local health care providers were trained to impart the BCC strategy: for example, 
AWWs held some 600 women's group meetings, attended, in total, by over 12,000 women.

\section{Challenges}

Several challenges were faced in the course of project implementation. For one, while the partnership with district government representatives was central, the relatively frequent transfer of key government officials affected the continuity of leadership, and required orienting new officials about the CAC model and addressing their concerns about its relevance.

The model faced several obstacles to improving the availability of services at PHC- and CHClevels. First, as mentioned earlier, was the lack of a suitable training facility in Tonk district; small abortion caseloads, inadequate infrastructure, a focus on the Janani Suraksha Yojana (JSY) programme (under the National Rural Health Mission) and a consequent lack of interest in the provision of abortion services, made the Tonk District Hospital an impractical option for upgrading as a training facility. At the same time, it was impractical to consider Ajmer Medical College as a training facility for the intervention as it is the only training facility catering to all the in-service training needs of the four districts, including Tonk, of Ajmer division. As neither of these were feasible options, the intervention had to identify, establish links with and strengthen another facility; thus, as one of the first activities of the intervention, the Zanana Hospital in Jaipur was identified and upgraded. However, this too had its limitations: as a busy training institution in Rajasthan, challenges were experienced in obtaining slots for training providers, often resulting in a 12-day training taking place over several weeks, and in obtaining permission for staff members from Tonk facilities to be deputed to an 'outside jurisdiction' (in a different district) facility.

Second, the frequent transfers of doctors trained by the intervention meant that several trained doctors were shifted out of the district, or to a facility within the district that did not contain the necessary equipment for abortion provision. Third, also impeding the pace at which provider training occurred was the fact that trainers were not available on a regular basis. Fourth, it was difficult to organise training for over 60 service providers that required a $2-3$ week stay in Jaipur due as much to the reluctance of providers to leave their home settings for this lengthy period as to that of their deputing authorities, particularly with regard to PHCs with a single medical officer. Indeed, during such occasions as Pulse Polio days and Family Planning weeks, training had to be suspended. Fifth, provider attitudes also posed an obstacle. For example, because of the strong drive against sex-selective abortion in Rajasthan, providers tended to be ambivalent with regard to safe abortion services and even the provision of first trimester abortions; at the same time, it was difficult to convince many doctors that MVA and MA are far superior techniques of abortion than is $\mathrm{D} \& \mathrm{C}$, and several remained unconvinced about providing abortion services to the unmarried or to victims of rape. Finally, the absence of basic amenities and facilities—from water to essential equipment—posed a huge challenge to the upgrading of facilities; indeed, even the District Hospital did not have an adequate space for providing abortions. The project 
made concerted efforts to overcome these challenges, including renovation of the abortion space at the District Hospital, and local government officials played a considerable role in supporting the project in doing so.

Challenges were also experienced in implementing community-level activities. For one, FPAI had planned that community-based activities would not be initiated until the completion of facility-based activities. Delays in completing facilitybased activities resulted, therefore, in delaying the initiation of the community-based programme. As a result, community-based activities took place for a year, and close engagement with women and other community members for just five months, clearly too short a period to effect major changes in awareness and practices. Second, and further compromising the community-based initiative, was the dearth of NGOs in the district, making it difficult to locate a single NGO that would cover the entire district, a hurdle that was circumvented by forming a network of NGOs with the Rajasthan Voluntary Health Association acting as the umbrella organisation. Third, women's lack of agency made it difficult for the intervention to reach many women, including the most vulnerable, that is, the young and the poor; at the same time it was difficult to assemble women and/or communities to attend group meetings, street plays and other gatherings, resulting, on occasion, in sparse attendance at these events and requiring multiple replays of docu-dramas and street plays. Fourth, at the same time, because of the general perceptions of the poor quality of services, long waiting times and frequent re-visit requirements at public sector facilities, the project experienced considerable difficulty in promoting the use of public sector facilities for abortion. Finally, it is not clear whether this generalised community-based approach to enhancing abortion-related awareness succeeded in reaching those most in need, that is, those in the childbearing ages and those with an unmet need for contraception.

The project made intense efforts to overcome these challenges, and local government officials played a considerable role in supporting the project in doing so. Nevertheless, we acknowledge that challenges faced in training providers and upgrading facilities posed serious delays to the roll out of the intervention, and, as a consequence, in the roll out of its community-based activities. The effective duration of the service delivery and communitybased BCC strategy implementation components consequently, was severely affected and far from adequate. 


\section{CHAPTER 4}

\section{Intervention effects on the health system}

This chapter assesses the extent to which exposure to the CAC model did indeed affect PHC and $\mathrm{CHC}$ readiness to provide comprehensive abortion care. Several changes that occurred at the health system level cannot be attributed to the intervention, for example, those relating to general infrastructure, staffing patterns and provision of reproductive health services other than abortion. The intervention sought to make changes in specific aspects of the health system, such as, for example, the availability of (a) safe abortion services; (b) trained abortion service providers; (c) IEC materials relating to abortion, relative to information available on other aspects of reproductive health; (d) abortion-related infrastructure, equipment and supplies; and (e) abortion-related services of good quality. This chapter also offers comparisons across districts as well as across intervention and non-intervention facilities in Tonk, the intervention district. Intervention effects are measured in terms of changes in various process indicators.

There is no doubt that the general situation of health facilities had improved in both districts. Over the three years during which the intervention was conducted, while the number of PHCs and CHCs in Tonk remained unchanged, in Bundi, one PHC and two CHCs were added. At the same time, many facilities experienced improvements in their general infrastructure and availability of services.

\section{Availability of abortion services}

Findings, presented in Table 4.1, confirm that a range of reproductive and child health services were offered by all the CHCs and almost all the PHCs. Indeed, at the PHC level (Panel A of the table), antenatal and postpartum care services and non-terminal contraception services were offered universally at the time of both surveys; delivery services, available in $82 \%$ and $96 \%$ of the PHCs in Tonk and Bundi, respectively, at baseline, became universally available by the time of the endline survey. Provision of sterilisation services also increased in Tonk: the percentage of PHCs providing tubal ligation and vasectomy increased from 73 to 93 and from 56 to 64, respectively; in contrast, there was no change in the percentage of PHCs in Bundi that provided tubal ligation (92\%) and a decline was observed in those offering vasectomy services (from 92\% to $84 \%$ ). While district-wise differences in availability of the above-mentioned reproductive health services were, for the most part, modest, differences in availability of abortion services were stark, clearly showing the influence of the intervention (Table 4.1). For example, as shown in Panel A, while at baseline, not a single PHC in either district was providing abortion services, this percentage increased to 18 in Tonk; in comparison, even at endline, not a single PHC in Bundi was providing abortion services.

At the CHC level (Panel B, Table 4.1), antenatal and postpartum services, as well as contraception and sterilisation services were universally available at both points in time. Abortion services, however, were not provided universally (at five of the seven CHCs in Tonk and two of the four and six CHCs at baseline and endline, respectively, in Bundi), with no change in the number providing 
Table 4.1

Constellation of services provided at PHCs and CHCs, Tonk and Bundi districts, Rajasthan

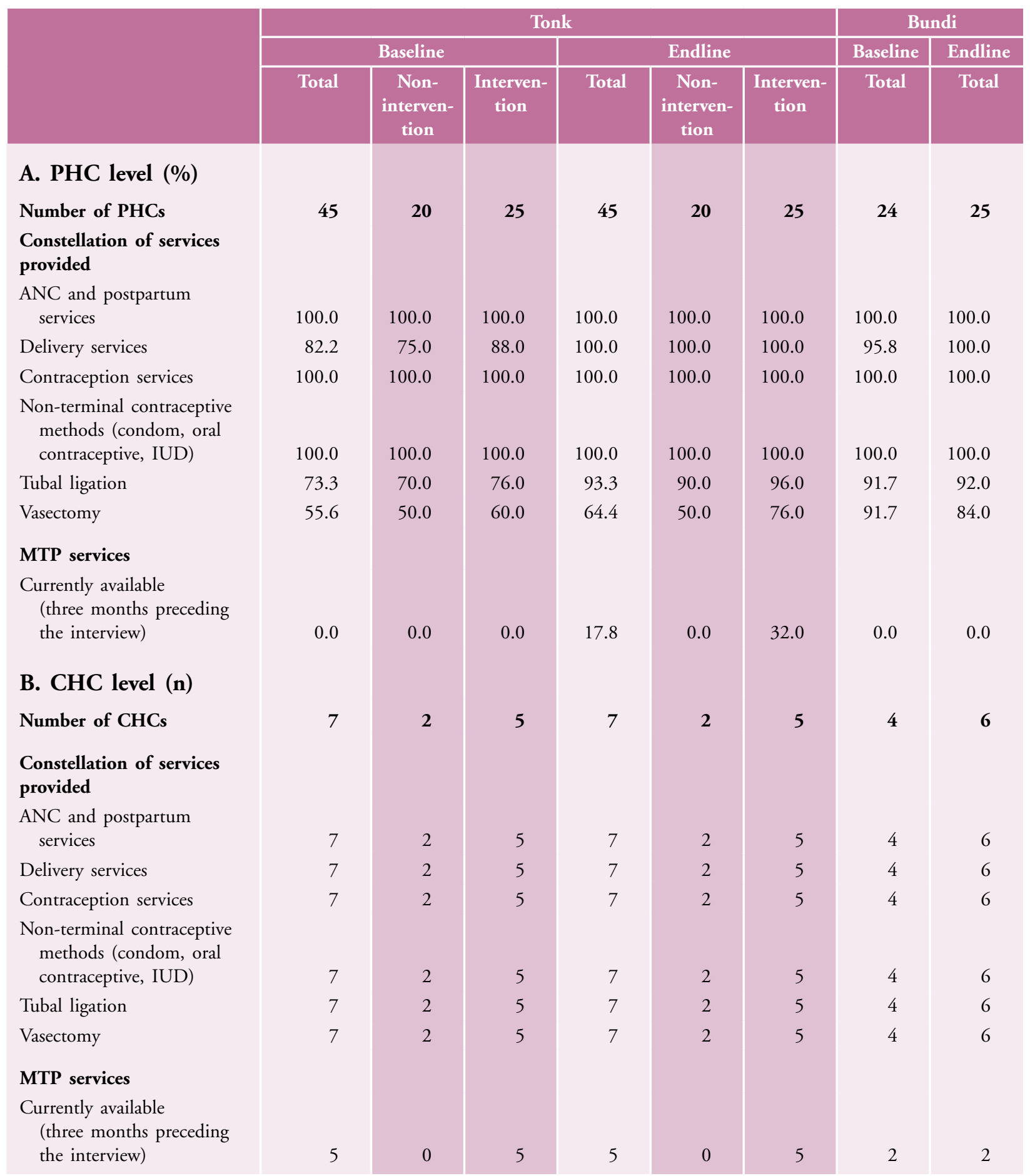


abortion services between the time of the two surveys.

A comparison of intervention and nonintervention PHCs in Tonk further underscores the contribution of the intervention to increasing the availability of abortion services: while these services were not offered at any PHC at baseline, they were offered at one-third (32\%) of the intervention PHCs at endline (eight of 25) compared to none of the 20 non-intervention PHCs (Panel A, Table 4.1). At the time of the endline survey, moreover, the two $\mathrm{CHCs}$ not providing abortion services were among the nonintervention facilities (Panel B, Table 4.1).

The staff position at PHC and CHC levels is presented in Table 4.2. Findings indicate that not all PHCs had even one medical officer at the time of the baseline survey $(87 \%$ and $96 \%$ in Tonk and Bundi, respectively); by endline, all PHCs had at least one medical officer, and the mean number of medical officers per PHC increased similarly in both districts, from $0.9-1.0$ at baseline to 1.4 at endline (Panel A, Table 4.2). Medical officers were, by and large, male and while the percentage of female medical officers increased somewhat in Tonk (from 13 to 18), it fell in Bundi (from 33 to 24). In contrast, the percentage of PHCs with the minimum required number of nursing staff (at least four) as per Government of India norms, increased in both districts: from 20 to 49 in Tonk, and sharply in Bundi (from 13 to 84 ).

Against this backdrop, the availability of MTPcertified providers at PHCs increased significantly over the intervention period in Tonk, and to a lesser extent, in Bundi. In Tonk (Panel A, Table 4.2), facilities with at least one MTP-certified provider registered a six-fold increase-from $7 \%$ at baseline to $42 \%$ at endline; in contrast, such facilities increased from $0 \%$ to $8 \%$ in Bundi.

At the CHC level (Panel B, Table 4.2), between the baseline and endline surveys, the mean number of doctors available at each facility fell from 6.3 to 5.9 in Tonk, and increased from 3.8 to 4.2 in Bundi. At both times, therefore, there were, on average, more doctors per $\mathrm{CHC}$ in Tonk than in Bundi. While each facility had at least one medical officer at both base- and end-line, the number of facilities with a female medical officer fell (from five to two) in Tonk, but increased (from two to five) in Bundi. There was little change, moreover, in the number of specialists at $\mathrm{CHCs}$ in both districts. As far as nursing staff are concerned, as in the case of PHCs (Panel A, Table 4.2), there was an increase in the number of facilities with nine or more nursing staff (from three to five in Tonk, and from none to four in Bundi), as well as in the mean number of staff per facility (from 7.6 to 11.3 in Tonk and from 6.0 to 11.3 in Bundi).

At the CHC level too (Panel B, Table 4.2), the number of facilities with a certified MTP provider increased from five to seven in Tonk; indeed, all CHCs had a certified MTP provider by the time of the endline survey; just five were providing abortion services. In contrast, the situation remained unchanged in Bundi, with just two CHCs reporting a certified provider at both points in time.

A comparison of intervention and nonintervention facilities in Tonk again underscores the contribution of the intervention. While just 
Table 4.2

Availability of trained abortion providers at PHCs and CHCs, Tonk and Bundi districts, Rajasthan

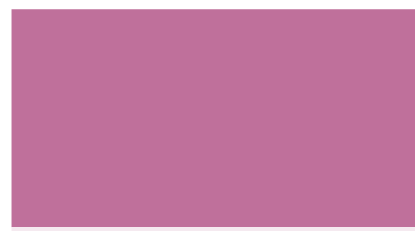

A. PHC level (\%) Number of PHCs

Availability of doctors

Mean number of doctors

Facilities with at least:

One medical officer

One female doctor

One MTP-certified doctor ${ }^{1}$

Availability of nursing staff

PHCs with at least four nursing staff

Mean number of nursing staff

\section{B. CHC level (n)}

Number of CHCs

Availability of doctors

Mean number of doctors

Facilities with at least:

One medical officer

One female doctor

One MTP-certified doctor ${ }^{2}$

One specialist

Four specialists

One obstetrician/ gynaecologist

One surgeon

Availability of nursing staff

Nine or more

Mean number of nursing staff

\begin{tabular}{|l|l|}
\hline & \\
\hline & \\
\hline
\end{tabular}

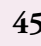

0.9

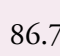

13.3

6.7

20.0

2.4

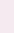

45

\begin{tabular}{|c|}
\hline Baseline \\
\hline $\begin{array}{c}\text { Non- } \\
\text { interven- } \\
\text { tion }\end{array}$ \\
\hline
\end{tabular}


$4 \%$ and $10 \%$ of intervention and non-intervention PHCs had a trained MTP provider at the time of the baseline survey, almost two in three intervention PHCs (64\%), compared to just $15 \%$ of the nonintervention facilities had a trained MTP provider by the time of the endline survey (Panel A, Table 4.2).

\section{Provider awareness and perceptions}

Provider awareness about abortion-related issues, did not, by and large, increase consistently over the period of the intervention (Table 4.3). For example, among PHC- and CHC-level medical officers in both districts, awareness that MA is provided only up to seven weeks of gestation fell slightly (from $100 \%$ to $90 \%$ ), that only MTPcertified MBBS doctors are permitted to prescribe
MA fell considerably (from $83-86 \%$ to $58-62 \%$ ), that the opinion of more than one registered doctor is required for second trimester abortions remained virtually unchanged (89-92\% in Tonk and $83-84 \%$ in Bundi), and that the consent of the husband (or guardian) is not necessary to conduct abortions of women aged 18 and above increased moderately in Tonk (by 7 percentage points) and considerably in Bundi (by 24 percentage points). By the time of the endline survey, all providers in both districts acknowledged the right of women to confidential counselling. Most providers, in addition, respected women's right to be informed about the procedure she is to undergo; though by endline, providers in Tonk were more likely than those in Bundi to do so (increase from $89 \%$ to $94 \%$ and $83-84 \%$, respectively).

\section{Table 4.3}

Awareness among PHC- and CHC-level medical officers about MTP and their perceptions about abortion and women's abortion-related rights, Tonk and Bundi districts, Rajasthan

\begin{tabular}{|c|c|c|c|c|}
\hline & \multicolumn{2}{|c|}{ Tonk } & \multicolumn{2}{|c|}{ Bundi } \\
\hline & Baseline & Endline & Baseline & Endline \\
\hline Number PHC- and CHC-level medical officers & $28^{1}$ & 52 & $23^{1}$ & 31 \\
\hline \multicolumn{5}{|l|}{ Awareness: $\%$ aware that: } \\
\hline MA is provided only up to 7 weeks of gestation & 100.0 & 90.4 & 100.0 & 90.3 \\
\hline Only MTP-certified MBBS doctors are permitted to prescribe MA & 85.7 & 61.5 & 82.6 & 58.1 \\
\hline $\begin{array}{l}\text { The opinion of more than one registered doctor is required for } \\
\text { abortions performed between } 12-20 \text { weeks of pregnancy }\end{array}$ & 89.3 & 92.3 & 82.6 & 83.9 \\
\hline $\begin{array}{l}\text { Consent of husband (or guardian) for abortion is not required for } \\
\text { women aged } 18 \text { and above }\end{array}$ & 67.9 & 75.0 & 43.5 & 67.7 \\
\hline \multicolumn{5}{|l|}{ Perceptions about women's rights: $\%$ who perceive that women should: } \\
\hline Undergo counselling privately & 96.4 & 100.0 & 87.0 & 100.0 \\
\hline $\begin{array}{l}\text { Be fully informed about the specifics of the medical procedure she } \\
\text { is to undergo }\end{array}$ & 89.3 & 94.2 & 82.6 & 83.9 \\
\hline
\end{tabular}

${ }^{1}$ Information from 24 and 5 PHCs in Tonk and Bundi, respectively, was not available. 


\section{Availability of IEC materials}

As evident from Panel A of Table 4.4, most PHCs in Tonk displayed materials on family planning (93\% at the time of both baseline and endline surveys), child health (91-93\%), and to a lesser extent, maternal health (64-67\%), and percentages so reporting remained virtually unchanged between the time of the two surveys. At the $\mathrm{CHC}$ level (Panel B of the table), almost all facilities in Tonk displayed these materials at both points in time. In Bundi, in contrast, while materials on these issues were displayed in $83-96 \%$ of PHCs at baseline, percentages displaying materials on child health and maternal health fell significantly between the times of the baseline and endline surveys (from 92\% and $83 \%$ to $76 \%$ and $56 \%$, respectively) (Panel A, Table 4.4). In contrast, there was a consistent increase in the number of $\mathrm{CHCs}$ displaying materials on each of these topics by the time of the endline survey (Panel B, Table 4.4).

Panel A of Table 4.4 further indicates that the availability of abortion-related information increased impressively in both settings and in both types of facilities. At baseline, materials on abortion were largely absent at PHCs, and those that provided information were more likely to focus on the illegality of sex-selective abortion (13\% and $29 \%$ in Tonk and Bundi, respectively) than on the legality and availability of abortion services $(2-4 \%$ of PHCs in both districts). By the time of the endline survey, the percentage of PHCs with materials on both sex-selective abortion and on the availability and legality of abortion increased considerably in Tonk: by 36 and 91 percentage points, respectively. In
Bundi, in contrast, while the percentage of PHCs displaying materials on the illegality of sex-selective abortion increased by 43 percentage points, none of the PHCs displayed any materials on the legality and availability of abortion (from $4 \%$ at baseline to $0 \%$ at endline). The increase in the number of PHCs displaying materials on the illegality of sex-selective abortion in both districts may be attributed to the widespread dissemination of information about the PCPNDT Act across Rajasthan; in contrast, the increase in the number of PHCs displaying materials on the legality and availability of abortion is attributable largely to the CAC intervention.

At the CHC level too, the increase in the availability of materials highlighting the legality and availability of abortion was far more evident in Tonk than in Bundi (Panel B, Table 4.4). In Tonk, for example, while four of the seven CHCs had displayed such materials at baseline, all seven had such materials available by endline. In Bundi, in contrast, only one $\mathrm{CHC}$ displayed such materials at both points in time. On the other hand, while the number of $\mathrm{CHCs}$ displaying materials on the PNDT Act remained constant in Tonk (five at both points in time), there was a marked increase in those displaying such information in Bundi (from one to six).

A comparison of intervention and nonintervention facilities in Tonk suggests, however, that the changes observed in the percentage of PHCs displaying materials on the legality of abortion increased somewhat more strikingly in the intervention PHCs (from $0 \%$ to $96 \%$ ) than in the non-intervention PHCs (from 5\% to 90\%). Increases 


\section{Table 4.4}

Availability of IEC materials in PHCs and CHCs, Tonk and Bundi districts, Rajasthan

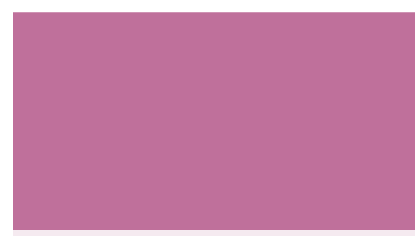

\section{A. PHC level (\%)}

Number of PHCs

IEC materials displayed

Child health including immunisation

Maternal health

Family planning (including posters, brochures, samples)

Illegality of sex-selection practices and abortion

Legality, availability of abortion

\begin{tabular}{|l|l|}
\hline & \\
\hline Total & \\
& \\
\end{tabular}

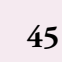

20

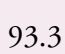

93.3

66.7

93.3

13.3

2.2

\section{B. CHC level (n)}

\section{Number of CHCs}

\section{IEC materials displayed}

Child health including immunisation

Maternal health

Family planning (including posters, brochures, samples)

Illegality of sex-selection practices and abortion

Legality, availability of abortion

45

Number of PHCs
IEC materials displayed
Child health including
immunisation
Maternal health
Family planning (including
posters, brochures,
samples)
Illegality of sex-selection
practices and abortion
Legality, availability of
abortion

3

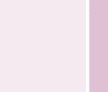

$$
65.0
$$

7

2

7

2

2

7

5

4

\begin{tabular}{|c|}
\hline Baseline \\
\hline $\begin{array}{c}\text { Non- } \\
\text { interven- } \\
\text { tion }\end{array}$ \\
\hline
\end{tabular}

\begin{tabular}{|c|}
\hline \multicolumn{2}{|r|}{ Tonk } \\
\hline $\begin{array}{c}\text { Interven- } \\
\text { tion }\end{array}$ \\
\hline
\end{tabular}

Tonk

\begin{tabular}{|c|c|}
\hline \multicolumn{2}{|c}{ Endline } \\
\hline Total & $\begin{array}{c}\text { Non- } \\
\text { interven- } \\
\text { tion }\end{array}$ \\
\end{tabular}

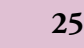

45

20

25

22

25

\begin{tabular}{r|r|r}
\hline & 90.0 & 96.0 \\
\hline 3.3 & 10.0 & 16.0 \\
\hline 2.2 & 5.0 & 0.0 \\
\hline
\end{tabular}

93.3

48.9

93.3

\begin{tabular}{r|r}
90.0 & 96.0 \\
2 & 5 \\
2 & \\
1 & 5 \\
2 & 5 \\
1 & 5 \\
2 & 5
\end{tabular}

5

91.1

95.0

88.0

91.7

76.0

64.4

60.0

68.0

83.3

56.0

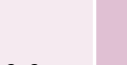

90.0

96.

45.0

7

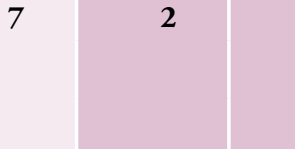

5

5
0
29.

4.2

0.0

100.0

72.0

6

6

5

\begin{tabular}{l|l|}
\hline 4 & 6 \\
\hline 1 & 6 \\
\hline 1 & 1
\end{tabular}


in PHCs displaying materials on the illegality of sex-selective abortion were equally evident in both intervention and non-intervention facilities (35-36 percentage points).

\section{Infrastructure and equipment}

\section{Facility and examination room infrastructure}

The intervention was not intended to influence the infrastructure of the facility or the examination room; and findings, presented in Table 4.5, suggest that infrastructure was typically more likely to be available in Bundi than in Tonk. Improvements over time were, however, more striking in some respects in Tonk, in other respects in Bundi. At the PHC level (Panel A, Table 4.5), for example, improvements were evident in both districts in the percentage of PHCs with at least four beds, but the increase was greater in Tonk than in Bundi (25 versus 13 percentage points). Similar increases were recorded in the percentage of PHCs that had regular access to transport (an increase of 29 and 26 percentage points in Tonk and Bundi, respectively). In contrast, improvements in the availability of piped water, also evident in both districts, were far smaller in Tonk than in Bundi (20 versus 59 percentage points) In summary, the percentage of PHCs with electricity, at least four beds, piped water and regular access to transport increased from 7 to 22 in Tonk, and, because of the large increase in PHCs with piped water, from 8 to 68 in Bundi.

Higher order facilities were better equipped (Panel B, Table 4.5). Electricity was available in all $\mathrm{CHCs}$ in both districts at both points in time. The availability of piped water increased considerably in both districts: from three of the seven $\mathrm{CHCs}$ to all seven $\mathrm{CHCs}$ in Tonk, and from one of the four to all six CHCs in Bundi. Access to transportation also increased in Tonk such that by the time of the endline survey, all seven facilities reported such access; in Bundi, just four of the six CHCs had access to transport at endline. As far as bed strength is concerned, the number of CHCs containing 30 or more beds (the norm established by the Government of India for CHCs) remained constant in Tonk (six of the seven CHCs), but increased in Bundi (from two of the four CHCs to all six). A summary measure of available infrastructure index-reflecting the availability of electricity, at least 30 beds, piped water and regular access to transport facilitiessuggests considerable increases across the intervention period, in both districts: from two to six of the seven $\mathrm{CHCs}$ in Tonk, and from none to four of the six CHCs in Bundi.

Table 4.6 presents the situation in the examination room of the PHCs and CHCs. Panel A shows that there was a decline in the percentages of PHCs reporting a separate room for examination, more pronounced in Bundi than in Tonk, (from $79-80 \%$ at baseline to $69 \%$ and $44 \%$ in Tonk and Bundi, respectively, at endline), a table for examination (from $96-100 \%$ at baseline to $78 \%$ and $60 \%$ in Tonk and Bundi, respectively, at endline) and auditory privacy (from $58-64 \%$ at baseline to $49 \%$ and $20 \%$ in Tonk and Bundi, respectively, at endline). At the same time, at the two points in time, visual privacy remained virtually unchanged at the PHC level in Tonk (from $73 \%$ to $76 \%$ ) but again, declined in Bundi (from $71 \%$ to $60 \%$ ). The 


\section{Table 4.5}

Availability of basic infrastructure at PHCs and CHCs, Tonk and Bundi districts, Rajasthan

\begin{tabular}{|l|l|l|l|l|}
\multicolumn{2}{|c|}{ Tonk } & \multicolumn{2}{|c|}{ Bundi } \\
\cline { 2 - 4 } & Baseline & Endline & Baseline & Endline \\
\cline { 2 - 3 }
\end{tabular}

\section{A. PHC level (\%)}

\section{Number of PHCs}

Basic infrastructure

Beds available

Mean number of beds

Four or more beds

\section{Electricity}

Electricity connected

\section{Telephone facility}

Landline telephone available

At least one staff has mobile

\section{Water supply}

Main source of water supply-piped water

Piped water in toilet

\section{Transport}

Can arrange transport at emergency, regularly

Facilities with electricity, at least four beds, piped water and regular transport facility

\section{B. CHC level (n)}

\section{Number of CHCs}

\section{Basic infrastructure}

\section{Beds available}

Mean number of beds

30 or more beds

\section{Electricity}

Electricity connected

\section{Telephone facility}

Landline telephone available

At least one staff has mobile

\section{Water supply}

Main source of water supply-piped water

Piped water in toilet

\section{Transport}

Can arrange transport at emergency, regularly

Facilities with electricity, at least 30 beds, piped water and regular transport facility
100.0

100.0 
Table 4.6

Examination room infrastructure at PHCs and CHCs, Tonk and Bundi districts, Rajasthan

\begin{tabular}{|l|l|l|l|l|}
\multicolumn{2}{|c|}{ Tonk } & \multicolumn{2}{|c|}{ Bundi } \\
\cline { 2 - 4 } & Baseline & Endline & Baseline & Endline \\
\hline
\end{tabular}

\section{A. PHC level (\%)}

Number of PHCs

Examination room/Operation Theatre (OT)

Separate room for examination

Table for examination

Visual privacy

Auditory privacy

Wash basin with running water

Operating table (with stirrups)

Facilities with separate examination room, visual privacy,

OT table with stirrups and wash basin with running water

\section{B. CHC level (n)}

\section{Number of CHCs}

\section{Examination room/Operation Theatre (OT)}

Separate room for examination

Table for examination

Visual privacy

Auditory privacy

Wash basin with running water

Operating table (with stirrups)

Facilities with separate examination room, visual privacy, OT table with stirrups and wash basin with running water

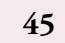

45

24

25

80.0

95.6

68.9

77.8

79.2

100.0

70.8

58.3

64.4

75.6

48.9

51.1

12.5

57.8

45.8

26.7

4.4

20.0

0.0

44.0

60.0

60.0

20.0

64.0

44.0

24.0

6

4

4 of facilities with a separate examination room, visual privacy, an operating table with stirrups and a wash basin with running water increased in both settings-from 4 to 20 in Tonk, and from none to 24 in Bundi.

At the CHC level, as shown in Panel B, Table 4.6, examination room infrastructure, in terms of a separate room for examination, an examination 
table, visual and auditory privacy, a wash basin with running water and an operating table with stirrups, was available in almost all facilities at baseline (5-7 of the seven CHCs in Tonk and 3-4 of the four in Bundi), and to a somewhat greater extent by endline (6-7 of the seven CHCs in Tonk and 4-6 of the six in Bundi).

\section{Essential equipment for the provision of abortion services}

In contrast to basic and examination room infrastructure, the intervention did indeed seek to enhance the availability of functioning essential equipment for the provision of abortion services. As Table 4.7 shows, there was an impressive increase in the availability of such equipment for the provision of abortion services in both districts, but clearly, improvements are more widely observed in Tonk than in Bundi.

At the PHC level, for example, in Tonk, there was a considerable increase, for the most part in the availability of functioning essential equipment, ranging from MVA suction machines to dilators (Panel A, Table 4.7). Correspondingly, changes over time in the availability of such equipment were more erratic in Bundi, with increases observed in some equipment (tenaculum/volsellum, suction cannulae and dilators, for example) and declines observed in others (EVA or MVA equipment). Finally, the percentage of PHCs with an autoclave drum remained unchanged in Tonk (56-58) but increased considerably in Bundi (from 58 to 76). In sum, there has been an increase in the percentages of PHCs containing all essential equipment in working condition (MVA or EVA suction machines, volsellum, cannulae and autoclave drums), from 9 to 20 in Tonk, and from 25 to 32 in Bundi. We note that despite the fact that not a single PHC in Bundi was providing abortion services at the time of the endline survey (Table 4.1) and just eight percent of all PHCs had a trained MTP provider (Table 4.2), one-third were equipped to do so. In comparison, in Tonk, almost all the PHCs that were so equipped $(20 \%)$ were providing abortion services (18\%). A comparison between non-intervention and intervention facilities in Tonk highlights that the availability of functioning essential equipment for the provision of abortion services has increased, on average, far more impressively in intervention facilities. For example, at baseline, not a single non-intervention PHC and just 16\% of the PHCs selected for intervention contained all of the functioning essential equipment required to provide abortions in working condition; by endline, while $36 \%$ of intervention PHCs had such equipment in place; none of the non-intervention PHCs had all of the essential equipment. At the $\mathrm{CHC}$ level, such distinctions were not observed (Panel B, Table 4.7).

\section{Abortion-related service delivery}

In this section, we explore service delivery issues in the facilities providing abortion services. As shown earlier, not a single PHC in Bundi provided abortion services at both baseline and endline, and in Tonk, services were provided only at endline. Hence, our discussion focuses on the service delivery issues in the intervention facilities in Tonk at the time of the endline survey (Table 4.8). 


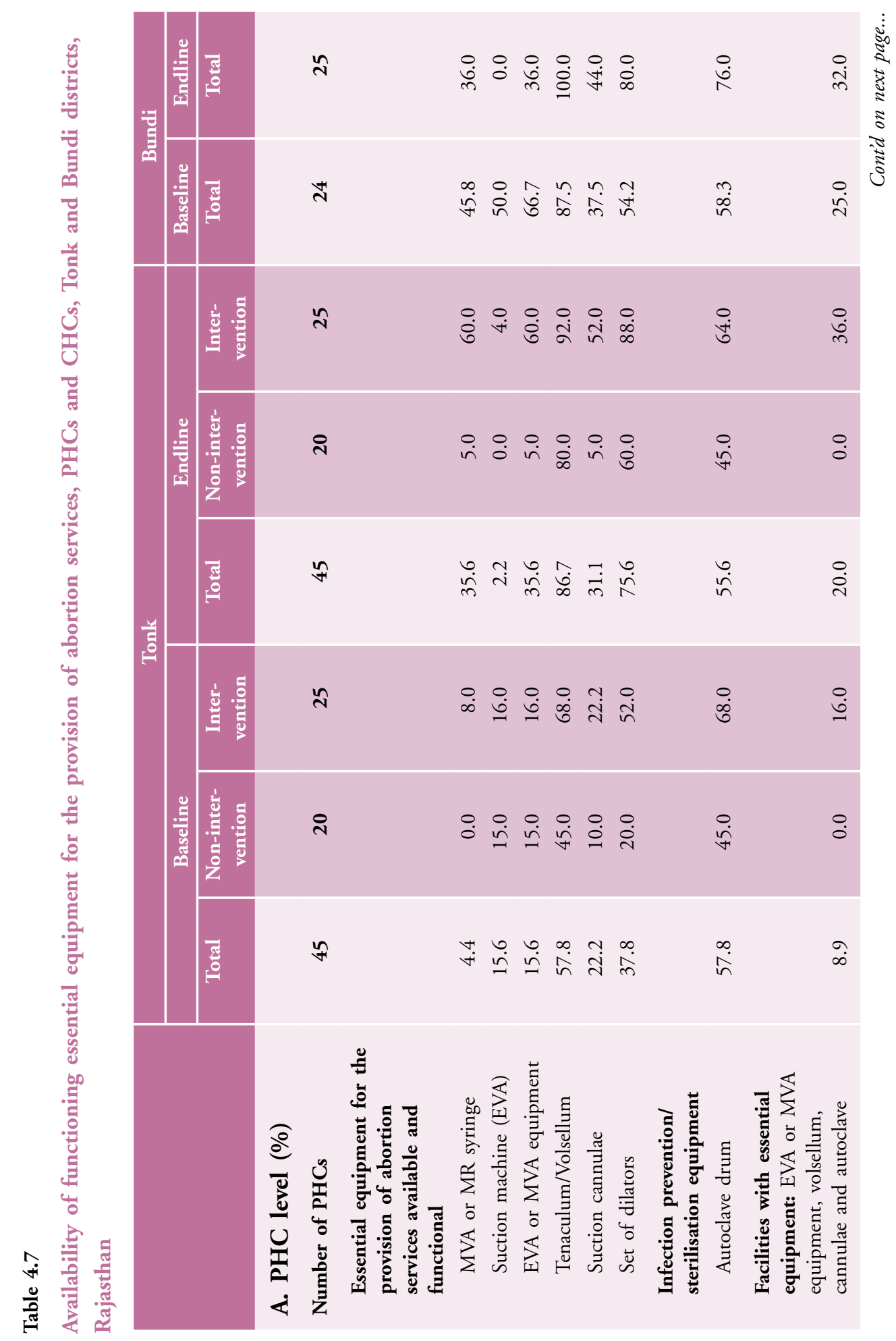




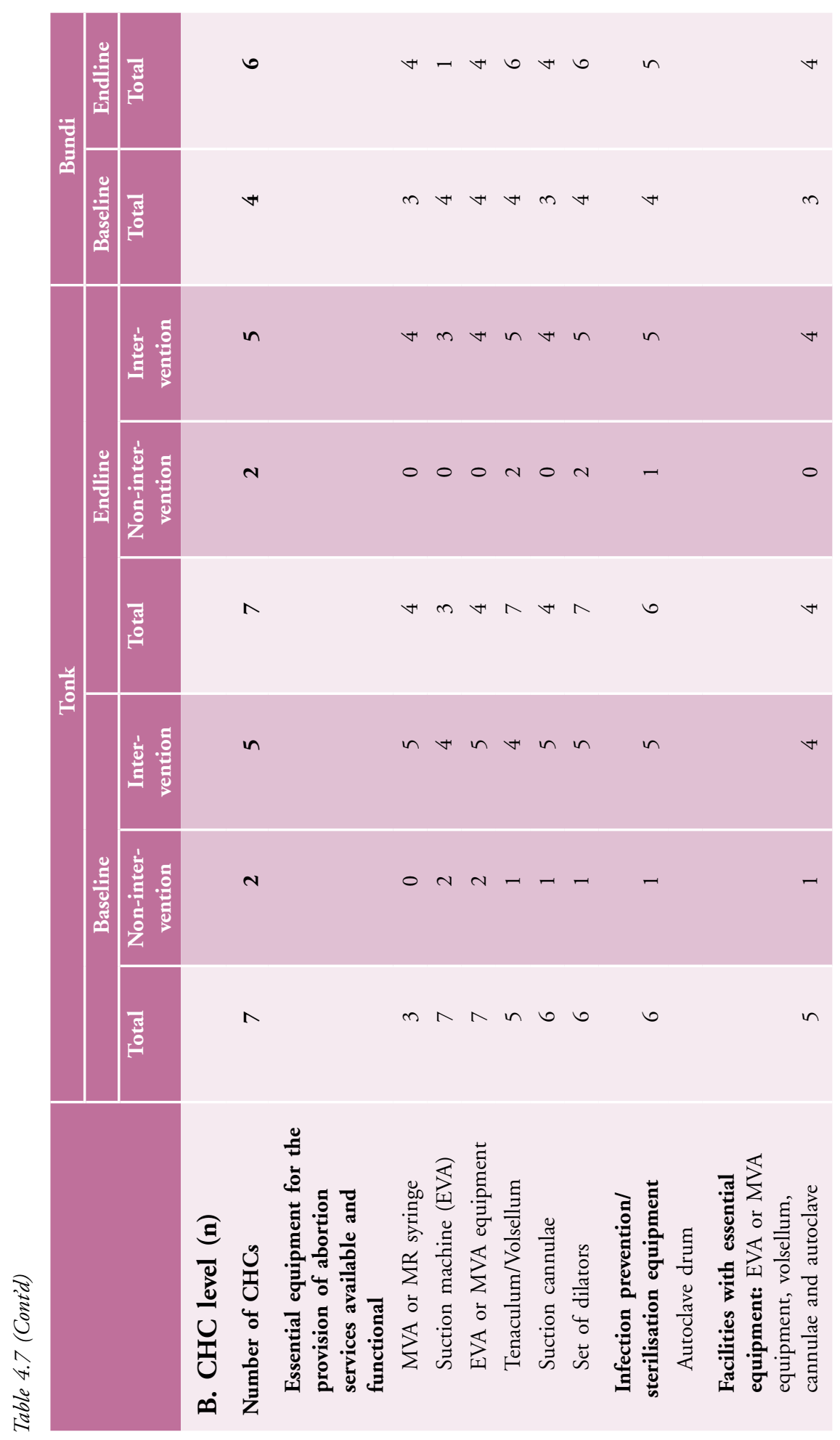


As shown in Table 4.8, Panel A, at the time of the endline survey, all of the eight PHCs in Tonk that provided abortion services at endline, provided first trimester abortions only; seven of the eight provided services for incomplete abortion.

Again, while the intervention succeeded in ensuring the readiness of these PHCs to provide abortion services, the abortion caseload was, by and large, small. Seven of the eight PHCs providing abortion in Tonk had conducted fewer than 50 abortions over the 12-month period preceding the endline survey, with an average of eight abortions in each PHC and a total of 107 in all eight. Notably, moreover, six PHCs were using MVA and two were using MA for first trimester abortions; at the same time, two PHCs reported the use of D\&C for abortions performed in the first trimester. Finally, seven of the eight PHCs reported that they provided abortion services more than two days a week or on demand.

At the time of the endline survey, all the PHCs in Tonk also reported providing post-abortion contraception services. However, several PHCs denied services to the young and unmarried: only three and five of the eight PHCs reported providing services to minors and the unmarried, respectively, and six of the eight provided abortion services to women without the husband's consent. On the day of the interview, written guidelines for abortion were available in all the PHCs providing abortion, and registers were maintained in all but one facility.

At the CHC level (Table 4.8, Panel B), the number of facilities providing abortion services remained unchanged in both districts (five and two in Tonk and Bundi, respectively). Just one $\mathrm{CHC}$ in Tonk and none of those in Bundi provided second trimester abortions; however all the CHCs in both districts provided services for incomplete abortion at the endline. As in the case of PHCs, here too, the number of abortions conducted was moderate: just three of the five CHCs in Tonk, and not a single $\mathrm{CHC}$ in Bundi reported conducting more than 100 abortions in the 12 months preceding the interview. The remaining two CHCs in Tonk and both those in Bundi conducted 50 or fewer abortions in the 12-month period. Nevertheless, in the year preceding the endline assessment, a total of 1,178 abortions had been performed at the CHC level in Tonk, compared to 42 in Bundi.

Findings also suggested that almost all the $\mathrm{CHCs}$ provided abortion services more than twice a week or on demand: three and four CHCs in Tonk at the time of the baseline and endline surveys, respectively, and both CHCs in Bundi, at both points in time.

The methods used for first trimester abortion suggest the continued use of $\mathrm{D} \& \mathrm{C}$ in several CHCs: four of the five in Tonk, and one of the two in Bundi. In contrast, just one $\mathrm{CHC}$ in each district reported the use of MVA/MR, EVA or MA.

All the CHCs provided post-abortion contraception. As far as provision of abortion to minors and the unmarried is concerned, however, in Tonk, the number doing so fell from 4-5 to three from baseline to endline; by endline, both facilities in Bundi were providing abortion to minors and the unmarried. Finally, one CHC each in Tonk and Bundi denied services to women without their husband's written consent. 


\section{Table 4.8}

PHCs and CHCs providing abortion, Tonk and Bundi districts, Rajasthan

\begin{tabular}{|l|l|l|l|l|}
\multicolumn{2}{|c|}{ Tonk } & \multicolumn{2}{|c}{ Bundi } \\
\cline { 2 - 4 } & Baseline & Endline & Baseline & Endline
\end{tabular}

\section{A. PHC level (n)}

\section{Number of PHCs providing abortion}

Services for second trimester abortion available

Services for incomplete abortions available

Number of abortions conducted (12 months preceding the interview $)^{1}$

50 or less

51-99

100 or more

Median number of abortions

Total number of abortions conducted

Provided abortion services $>2$ days a week or on demand

\section{Method used for first trimester abortions ${ }^{2}$ \\ MVA/MR \\ EVA \\ $\mathrm{D} \& \mathrm{C}$ \\ MA}

Provided post-abortion contraception Abortion provided to minors Abortion provided to the unmarried

Husband's (or guardian's) signature mandatory for abortion Written guidelines available at facility MTP register maintained at facility

\section{B. CHC level (n)}

\section{Number of CHCs providing abortion}

Services for second trimester abortion available Services for incomplete abortions available

Number of abortions conducted (12 months preceding the interview) ${ }^{3}$

50 or less

51-99

100 or more

Total number of abortions conducted

Provided abortion services $>2$ days a week or on demand

\begin{tabular}{|c|c|c|c|}
\hline 0 & 8 & o & o \\
\hline- & 0 & - & - \\
\hline- & 7 & - & - \\
\hline- & 7 & - & - \\
\hline- & 1 & - & - \\
\hline- & 0 & - & - \\
\hline- & 8 & - & - \\
\hline- & 107 & - & - \\
\hline- & 7 & - & - \\
\hline- & 6 & - & - \\
\hline- & 0 & - & - \\
\hline- & 2 & - & - \\
\hline- & 2 & - & - \\
\hline- & 8 & - & - \\
\hline- & 3 & - & - \\
\hline- & 5 & - & - \\
\hline- & 6 & - & - \\
\hline- & 8 & - & - \\
\hline- & 7 & - & - \\
\hline 5 & 5 & 2 & 2 \\
\hline 0 & 1 & 0 & 0 \\
\hline 4 & 5 & 1 & 2 \\
\hline 3 & 2 & 1 & 2 \\
\hline 1 & 0 & 0 & 0 \\
\hline 1 & 3 & 1 & 0 \\
\hline 81 & 1,178 & 390 & 42 \\
\hline 3 & 4 & 2 & 2 \\
\hline
\end{tabular}


Table 4.8 (Cont'd)

\begin{tabular}{|c|c|c|c|c|}
\hline & \multicolumn{2}{|c|}{ Tonk } & \multicolumn{2}{|c|}{ Bundi } \\
\hline & Baseline & Endline & Baseline & Endline \\
\hline \multicolumn{5}{|l|}{ Method used for first trimester abortions ${ }^{2}$} \\
\hline MVA/MR syringe & 1 & 1 & 0 & 1 \\
\hline EVA & 0 & 1 & 0 & 0 \\
\hline $\mathrm{D} \& \mathrm{C}$ & 4 & 4 & 1 & 1 \\
\hline MA & 0 & 1 & 1 & 1 \\
\hline Refer elsewhere & 0 & 1 & 2 & 0 \\
\hline Provided post-abortion contraception & 5 & 5 & 2 & 2 \\
\hline Abortion provided to minors & 5 & 3 & 2 & 2 \\
\hline Abortion provided to the unmarried & 4 & 3 & 1 & 2 \\
\hline Husband's (or guardian's) signature mandatory for abortion & 4 & 4 & 2 & 1 \\
\hline Written guidelines available at facility & 5 & 3 & 2 & 2 \\
\hline MTP register maintained at facility & 3 & 4 & 2 & 1 \\
\hline
\end{tabular}

An MTP register was maintained in four of the five CHCs in Tonk and one of the two in Bundi at the time of the endline interview; written guidelines were available in three and two $\mathrm{CHCs}$, respectively.

\section{Summary}

Findings highlight that even by the time of the endline survey, abortion services were much less likely to be provided than were other reproductive health services, including pregnancy-related services, tubal ligation and contraceptive services. Indeed, at the PHC level, abortion services were not provided in Bundi, the control district, at both baseline and endline; in comparison, abortion services, not available in a single PHC in Tonk, the intervention district, at the time of the baseline survey, became available in almost one in five PHCs in general, and one-third of all intervention PHCs, by the time of the endline inquiry, indicating that the intervention had a considerable effect on increasing the availability of services at the PHC level. At the $\mathrm{CHC}$ level, in contrast, there was no change in the number of facilities providing abortion services (five and two in Tonk and Bundi, respectively).

At the time of the endline survey, MTPcertified medical officers were available in $42 \%$ of all PHCs in Tonk district, compared to in just $8 \%$ of all PHCs in Bundi. Clearly, there was a far more striking increase in the availability of MTP-certified providers at the PHC level in Tonk than in Bundi: of 36 and 8 percentage points, 
respectively. In addition, in Tonk district, $64 \%$ of all intervention PHCs, compared to just $15 \%$ of non-intervention PHCs reported a certified MTP provider, highlighting the effect of the intervention on expanding the provider base at the PHC level. At the $\mathrm{CHC}$ level, the number of facilities with a certified MTP provider increased from five to seven in Tonk; indeed, all CHCs had a certified MTP provider by the time of the endline survey. In contrast, the situation remained unchanged in Bundi, with just two CHCs reporting a certified MTP provider at the time of both surveys.

Displays of IEC materials on the legality and availability of abortion also increased impressively in Tonk (from 2\% to $93 \%$ of all PHCs, and from four to seven $\mathrm{CHCs}$ ); compared to no change in Bundi (from $4 \%$ to $0 \%$ of the PHCs and in one $\mathrm{CHC}$ at both points in time). Increases in PHCs with functioning essential equipment required for the provision of abortion services were somewhat higher in Tonk than in Bundi and (7 percentage points, respectively); changes were less evident at the CHC level. Finally, improvement, in general, in provider awareness about the conditions for performing abortions was inconsistent; by the time of the endline survey, however, all providers in both districts acknowledged the right of women to confidential counselling. Most providers, in addition, respected women's right to be informed about the procedure she is to undergo; though by endline, providers in Tonk were more likely than those in Bundi to do so (increase from $89 \%$ to $94 \%$ and $83-84 \%$, respectively).

While the provision of abortion services at the PHC level was initiated in eight PHCs in Tonk as a result of the intervention, the abortion caseload per PHC was typically small (not a single PHC in Bundi provided abortion services). Indeed, in total, these eight PHCs had conducted 107 abortions in the 12 months prior to the endline survey. The caseload over the same period was, as expected, higher among $\mathrm{CHCs}$, with three of the five facilities in Tonk and none in Bundi, providing more than 100 abortions.

Findings suggest moreover, that second trimester abortions were provided in just one $\mathrm{CHC}$ in Tonk and neither of those in Bundi. Services for incomplete abortion were available in seven of the eight PHCs in Tonk that provided abortion services, and all of the CHCs in both districts doing so. Methods used for first trimester abortion suggest the continued use of $\mathrm{D} \& \mathrm{C}$ for first trimester abortions: this method was used in two of the eight PHCs and four of the five CHCs in Tonk, and one of the two in Bundi. Use of medical abortion was rare in both PHCs and CHCs, reported by just two of the eight PHCs and one of the five CHCs in Tonk and one of the two CHCs in Bundi.

The intervention-in terms of facilitystrengthening and training of providers-was conducted in more than half of all PHCs in Tonk, and at the time of the endline survey, abortion services were provided in slightly less than one-fifth of all PHCs in Tonk. A comparison of indicators in intervention and non-intervention PHCs in Tonk underscores the role of the intervention in increasing access to abortion services. By the time of the endline survey, one-third of the intervention PHCs were providing abortion services, compared to not a single non-intervention PHC. Likewise, the 
availability of trained providers, IEC materials and functioning essential equipment for the provision of abortion services were systematically more available in intervention than non-intervention PHCs. In the case of $\mathrm{CHCs}$, changes were not apparent in terms of the number of facilities providing abortions between the time of the baseline and endline assessments, or the extent to which IEC materials were displayed and equipment was available; however, the number of trained providers increased from five to seven between the baseline and endline surveys; while MTP trained providers were available at intervention facilities at both baseline and endline, MTP-trained providers increased from none to two $\mathrm{CHCs}$ between baseline and endline in non-intervention $\mathrm{CHCs}$, perhaps the result of the provider training efforts of the intervention. As far as the number of abortions conducted is concerned, the eight PHCs in Tonk had conducted 107 abortions in the year preceding the endline survey (compared to none in the year preceding the baseline survey); $\mathrm{CHCs}$ in Tonk conducted a large number of abortions - 1,178 - in the year preceding the endline survey, representing a fourfold increase as compared to the year preceding the baseline survey (281), and far larger than the number conducted in the year preceding the endline survey in the two CHCs in Bundi, providing abortion services. 


\section{CHAPTER 5}

\section{Intervention effects on abortion-related awareness among women}

As noted earlier, the community-based intervention was implemented in the villages served by the PHCs and CHCs in which the facility-level intervention was conducted This chapter presents findings from the community-based survey relating to women's awareness of various factors relating to abortion and the effect of the intervention on such awareness. It begins by describing the kinds of abortion-related information that respondents had received during the year prior to the interview and the sources of that information, and follows this by a discussion of the levels of awareness of methods of abortion (surgical, medical or other methods, including locally available abortion-inducing preparations), the location of facilities providing abortion and the conditions under which abortion may be legally accessed. It then presents findings relating to the effect of the intervention on information obtained and on women's abortion-related awareness.

Both bivariate and multivariate associations are provided that compare respondents' endline and baseline responses to ascertain the extent of change in the above indicators attributable to exposure to the community intervention. Using pooled data from the baseline and endline surveys, logistic regression models were used to calculate the differencein-difference (DiD) estimate for each outcome indicator. The $\mathrm{DiD}$ estimate enables us to assess the net effect of exposure to the intervention on various outcome indicators after controlling for potentially confounding factors. Explanatory variables include a dummy variable indicating the time of the survey (baseline $=0$ and endline $=1$ ), variables indicating women's exposure to the intervention (not exposed=0 and exposed=1), a dummy variable for exposure to the intervention in the endline survey (the $\mathrm{DiD}$ estimate), and socio-demographic characteristics of women such as age, education, children ever born, household economic status and previous experience of abortion. In the regression models, respondents from Bundi were compared with those from Tonk after controlling for all the above confounding factors. The DiD estimates, shown as odds ratios, enable us to derive the impact of the district-level model intervention.

\section{Abortion-related information: Sources and messages}

In order to assess the reach of the communication strategy, all respondents were asked whether they had received any information about abortion in the year preceding the interview, and more specifically, the sources of such information. Findings, presented in Table 5.1, highlight that more women had received information about abortion in the year preceding the endline survey than had those in the year preceding the baseline survey: the increase was significant in Tonk-from 20\% to 25\%,-and moderate in Bundi, from $17 \%$ to $20 \%$ (Panel A). The leading source of information for women in both districts at the time of the end line survey was the mass media, that is, the television, radio, newspapers, and magazines, and in Tonk, docu-dramas, community radio shows, posters and billboards that formed a major part of 
the BCC intervention: percentages of women so exposed increased significantly over the intervention period, from 7 to 18 in Tonk, compared to 8 to 14 in Bundi. On the other hand, percentages of women obtaining information through interpersonal contacts (IPC), group meetings and wall signs remained virtually unchanged in both districts (from 14 to 17 in Tonk, and from 12 to 11 in Bundi). We note that three-quarters of the women who were interviewed had no education, and therefore, were unlikely to report such sources of information as the print media, posters, billboards and wall signs.

To assess the net effect of exposure to the intervention on women's access to information about abortion and discussion of abortion in informal networks in the year preceding the interview, logistic regression analyses were conducted to obtain the DiD estimate, after controlling for potentially confounding factors. The findings, presented in Panel B, Table 5.1, suggest that differences observed in the bivariate comparisons with regard to access

\section{Table 5.1}

Effects of the intervention on information received by women on abortion, Tonk and Bundi districts, Rajasthan

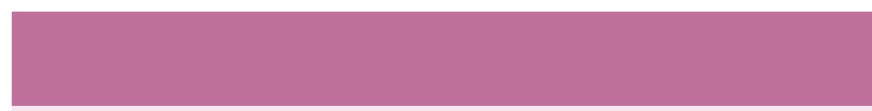

\begin{tabular}{|c|c|c|c|}
\hline \multicolumn{2}{|c|}{ Tonk } & \multicolumn{2}{c|}{ Bundi } \\
\hline Baseline & Endline & Baseline & Endline \\
\hline $\mathbf{9 4 0}$ & $\mathbf{9 2 2}$ & $\mathbf{1 , 0 1 3}$ & $\mathbf{9 2 5}$ \\
\hline
\end{tabular}

\section{A. Bivariate results $(\%)$}

\section{Formal sources of information about abortion}

Received information from any source

19.7

$25.1^{* *}$

17.4

19.5

Received information from ${ }^{1}$ :

Mass media (TV, radio, newspaper, magazine, poster/bill board, community radio etc.)

7.3

13.6

IPC $^{2}$, group meetings, wall signs, street plays $\mathrm{IPC}^{2}$

Group meetings

Wall sign in the village

Street play or docu-drama
1.5

$-\quad 5.3$

$-$
7.9

11.8

11.8

0.1

$-$

$-$
$13.8^{* * *}$

10.6 $3.4^{* * *}$

$1.1^{* *}$

6.9

0.3

\section{B. Multivariate results (odds ratio, DiD estimate) ${ }^{3}$}

Received information from at least one formal source ${ }^{4}$

Received information from IPC ${ }^{2}$, group meetings, wall signs, docu-drama or street plays ${ }^{4}$

${ }^{*} p<=0.10 ;{ }^{*} p<=0.05 ;{ }^{* *} p<=0.01 ;{ }^{* * *} p<=0.001$

${ }^{1}$ Multiple responses possible.

${ }^{2}$ Includes health care providers from public or private sector facilities.

${ }^{3}$ Odds ratios greater than 1.0 imply a positive net effect.

${ }^{4}$ Controlling age, years of education attained, total number of children ever born and standard of living index. 
to information from any formal source and from interpersonal contacts, group meetings and wall signs, and exposure to all sources of information including the mass media continued to be significant after controlling for potentially confounding factors.

As far as the content of communication is concerned, findings from Table 5.2 suggest that the leading message reported by more than half of all women in both districts was on restrictions on sex-selective abortion and the prescriptions of the Pre-conception and Pre-natal Diagnostic Techniques
(PCPNDT) Act. However, women in Tonk were significantly more likely than their counterparts in Bundi to report messages relating to the availability of medical abortion (36\% versus $23 \%$ ) and the availability of abortion services in public health facilities ( $25 \%$ versus $12 \%$ ), and significantly less likely to report messages about abortion being illegal or wrong ( $1 \%$ versus $6 \%)$. Other messages-relating to the legality of abortion (21-24\%), the importance of early abortion (13\%), and the importance of contraception to prevent unwanted pregnancy

\section{Table 5.2}

Messages received by women who reported receiving information on abortion in the year preceding the endline interview by source of message, Tonk and Bundi districts, Rajasthan

\begin{tabular}{|c|c|c|c|c|c|c|}
\hline & \multicolumn{2}{|c|}{ Any source } & \multicolumn{2}{|c|}{ Mass media } & \multicolumn{2}{|c|}{$\begin{array}{l}\text { IPC, group meetings, wall } \\
\text { signs, docu-dramas or } \\
\text { street plays }\end{array}$} \\
\hline & Tonk & Bundi & Tonk & Bundi & Tonk & Bundi \\
\hline \multicolumn{7}{|l|}{ Messages (\%) } \\
\hline $\begin{array}{l}\text { Abortion is legal, can be conducted } \\
\text { up to } 20 \text { weeks, in case of } \\
\text { contraceptive failure, in case of } \\
\text { rape, if the woman's health is in } \\
\text { danger, or if there is a serious } \\
\text { defect in the baby }\end{array}$ & 20.8 & 24.4 & 17.1 & 22.7 & 18.3 & 22.5 \\
\hline Early abortion is safe for a woman & 12.6 & 12.8 & 7.7 & 7.0 & 12.4 & 15.3 \\
\hline $\begin{array}{l}\text { Abortion services are available at } \\
\text { public sector facilities }\end{array}$ & 25.1 & $12.2^{* *}$ & 10.6 & 6.3 & 28.1 & $15.3^{*}$ \\
\hline $\begin{array}{l}\text { Unwanted pregnancy can be } \\
\text { prevented by regular use of } \\
\text { contraception }\end{array}$ & 32.0 & 29.4 & 14.7 & $24.2^{*}$ & 35.3 & 26.5 \\
\hline $\begin{array}{l}\text { Sex-selective abortion is illegal in } \\
\text { India }\end{array}$ & 58.0 & 51.7 & 64.7 & 60.2 & 30.1 & 40.8 \\
\hline $\begin{array}{l}\text { Pills are available that can terminate } \\
\text { a pregnancy }\end{array}$ & 35.9 & $22.8^{* *}$ & 34.1 & $21.9^{*}$ & 22.2 & 15.3 \\
\hline Abortion is a sin/wrong/illegal & 1.3 & $6.1^{*}$ & 5.9 & $4.7^{*}$ & 1.3 & 5.1 \\
\hline $\begin{array}{l}\text { Number of women exposed to } \\
\text { messages }\end{array}$ & 231 & 180 & 170 & 128 & 153 & 98 \\
\hline
\end{tabular}

${ }^{*} p<=0.05 ;{ }^{* *} p<=0.01 ;{ }^{* * *} p<=0.001$ 
(29-32\%) — were equally likely to be reported by women in both districts. Messages relating to sexselective abortion and the availability of medical abortion were more likely to be transmitted through the mass media, and those on the availability of abortion in public sector facilities, the importance of early abortion and of contraception were more likely to be transmitted through interpersonal contacts, group meetings and so on, and this pattern was fairly consistent over both districts.

\section{Awareness of abortion methods}

Table 5.3 presents the endline and baseline responses of respondents from the intervention and control districts to questions relating to awareness of whether a pregnancy can be terminated, and about specific methods of abortion. Unfortunately, at baseline, we did not probe the exact nature of the oral medication that some women had reportedly used to terminate their pregnancy but textual data suggest that many of these women were referring to the variety of Ayurvedic and other available abortioninducing preparations rather than the mifepristonemisoprostol combination; at endline, we included additional probing questions to ensure awareness of the mifepristone-misoprostol combination.

Findings presented in Panel A, Table 5.3 indicate that the large majority-about fourfifths - of women in both districts were aware, at the time of both baseline and endline surveys that a pregnancy can be terminated. Awareness of surgical methods of abortion increased significantly, by 13

\section{Table 5.3}

Effects of the intervention on women's awareness of abortion methods, Tonk and Bundi districts, Rajasthan

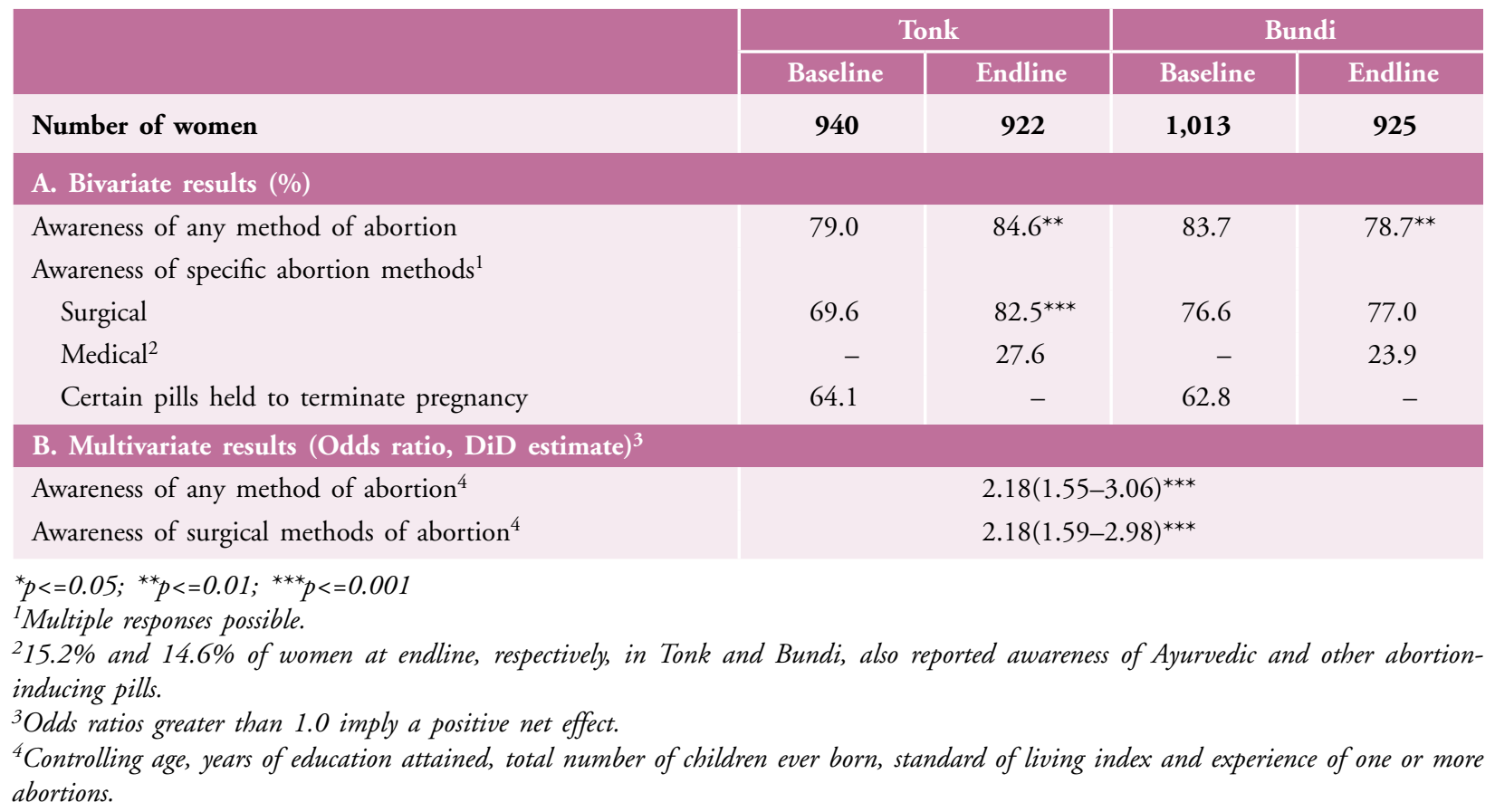


percentage points, in Tonk, but remained unchanged in Bundi. At baseline, a similar proportion of women from both districts-almost two-thirdsreported awareness of "some" pills that can terminate a pregnancy. As mentioned above, we were unable to assess levels of awareness of medical abortion at baseline, but an endline comparison suggests that the levels were marginally higher in Tonk than in Bundi (28\% versus $24 \%$ ).

The results of the logistic regression analysis, using the DiD model, are presented in Panel B, Table 5.3. Findings show that after controlling for potentially confounding factors and time, the net effect of the intervention on both awareness that pregnancy can be terminated by any method as well as by surgical methods specifically, was positive and significant.

\section{Awareness of facilities providing abortion services}

The community-level intervention sought to inform women in Tonk about the availability of abortion services in public sector facilities. Findings (Panel A, Table 5.4), show that awareness that abortion is provided at public sector facilities remained virtually unchanged in Tonk (79-82\%), but fell significantly, from $84 \%$ to $76 \%$, in Bundi. Corresponding with the thrust of the intervention, however, awareness that abortions are available at $\mathrm{CHCs}$ and $\mathrm{PHCs}$ increased significantly among women in both districts (by 17 percentage points in Tonk and 22 percentage points in Bundi). Again, in both districts, there was a significant increase in awareness of private sector availability of abortion services (from $29-31 \%$ at baseline to $40 \%$ in both settings at endline) and a significant decrease in awareness of the availability of abortion services from unqualified providers (from $47-50 \%$ at baseline to $14-15 \%$ at endline). Just $1-4 \%$ of the women in both districts were aware of likely unsafe sources of abortion at both points in time. Findings from the $\mathrm{DiD}$ analysis confirm that the intervention did not influence women's awareness of facilities providing abortion (not shown in table).

\section{Awareness of legal issues related to abortion}

Given the lack of awareness about the conditions under which abortion is legal in India, an important component of the community-level intervention was to raise awareness and rectify misconceptions about the conditions under which abortion is legal. Questions regarding awareness of the legality of abortion probed the extent to which women held misperceptions about the legal status of abortion in a host of situations, as described in Table 5.5. Findings confirm that misperceptions about conditions in which abortion is legal have declined significantly in both settings: the percentage misperceiving that abortion is illegal in at least one valid situation fell from 71 to 61 in Tonk, and more steeply, from 74 to 55 in Bundi. However, percentages reporting misperceptions in almost all valid conditions (5-6 of six) also fell significantly in both districts, now more significantly in Tonk ( 9 percentage points) than in Bundi (4 percentage points). 


\section{Table 5.4}

Percentage of women who were aware of facilities providing abortion, Tonk and Bundi districts, Rajasthan

\begin{tabular}{|c|c|c|c|c|}
\hline & \multicolumn{2}{|c|}{ Tonk } & \multicolumn{2}{|c|}{ Bundi } \\
\hline & Baseline & Endline & Baseline & Endline \\
\hline Number of women & 940 & 922 & 1,013 & 925 \\
\hline $\begin{array}{l}\text { Awareness of public or private sector facilities/providers of } \\
\text { abortion services (\%) }\end{array}$ & 78.9 & 81.8 & 84.3 & $75.6^{* * *}$ \\
\hline Any public sector facility ${ }^{1}$ & 76.8 & 78.2 & 83.7 & $71.9^{* * *}$ \\
\hline District Hospital & 45.3 & $35.9^{* * *}$ & 66.4 & $61.3^{*}$ \\
\hline $\mathrm{PHC}$ or $\mathrm{CHC}$ & 60.9 & $78.2^{* * *}$ & 50.2 & $71.9^{* * *}$ \\
\hline Private sector facility/doctor & 28.9 & $40.1^{* * *}$ & 31.3 & $39.9^{* * *}$ \\
\hline Awareness of other providers of abortion services ${ }^{1}$ & 47.1 & $15.2^{* * *}$ & 49.7 & $14.2^{* * *}$ \\
\hline ANM/Nurse & 16.6 & $1.3^{* * *}$ & 15.8 & $1.3^{* * *}$ \\
\hline Chemist & 36.5 & $14.3^{* * *}$ & 46.7 & $13.5^{* * *}$ \\
\hline Awareness only of likely unsafe sources of abortion & 4.0 & $1.2^{* * *}$ & 3.4 & 2.3 \\
\hline
\end{tabular}

Misperceptions regarding individual conditions under which abortion is legal, however, remain quite widespread, and declines in misperceptions about each condition were uneven across the two districts. For example, as shown in Table 5.5, percentages of women who believed that an unmarried woman and a woman whose pregnancy results from contraceptive failure cannot legally access abortion hardly changed from baseline ( 43 and 46, respectively) to endline (47 and 46, respectively) in Tonk, but declined significantly in Bundi (from 52 to 44 and from 45 to 40 , respectively). At the same time, both districts recorded significant declines_of 11 to 17 points-in the percentages of women who considered that it is illegal for a woman whose pregnancy results from rape, whose health is endangered or whose foetus faces risks, to undergo an abortion. The two issues about which misconceptions were rarely held at endline were that it is illegal for a woman who is more than 20 weeks pregnant to undergo abortion $(2-4 \%)$ and that sex-selective abortion is illegal (3-5\%).

Even so, the large majority of women continued to believe that a woman undergoing abortion needs her husband's consent. In both districts, however, percentages reporting this misconception declined between the time of the baseline and endline surveys, though the decline was far greater in Tonk (from 96 to 76) than in Bundi: (from 98 to 88 ).

The results of the logistic regression analysis, using the DiD model to compare changes in awareness of the legality of abortion between baseline and endline respondents in Tonk and Bundi, also shown in Table 5.5, suggest mixed 


\section{Table 5.5}

Effects of the intervention on misperceptions held by women about the legality of abortion and awareness of at least one situation in which abortion is legal, Tonk and Bundi districts, Rajasthan

\begin{tabular}{|l|c|c|c|c|}
\hline & \multicolumn{3}{|c|}{ Tonk } & \multicolumn{2}{|c|}{ Bundi } \\
\hline Number of women & Baseline & Endline & Baseline & Endline \\
\hline A. Bivariate results (\%) & 940 & $\mathbf{9 2 2}$ & $\mathbf{1 , 0 1 3}$ & $\mathbf{9 2 5}$ \\
\hline
\end{tabular}

\section{Awareness of legality of abortion}

Misperceives that abortion is illegal in at least one valid condition

Holds 5-6 misperceptions (of 6 conditions)

Misperceptions held: \% women reported that it is illegal

For a married woman to access abortion

For an unmarried woman to access abortion

For a woman whose pregnancy results from contraceptive failure ("accidentally") to access abortion

For a woman whose pregnancy has resulted from rape to access abortion

For a woman whose health is endangered by the pregnancy to access abortion

If there is a strong chance of foetal malformation, for a woman to access abortion

For a woman who is more than 20 weeks pregnant to access abortion

If the foetus is female

70.7

28.9

$61.2^{* * *}$

74.0

$55.2^{* * *}$

$19.9^{* * *}$

23.6

$19.7^{*}$

NA

43.4

35.5

NA

28.1

46.2

47.1

51.9

$44.3^{\text {** }}$

46.2

46.0

45.0

$39.6^{*}$

47.6

$36.8^{* * *}$

46.7

$33.2^{* * *}$

42.6

$25.6^{* * *}$

36.3

$22.9^{* * *}$

41.5

$28.1^{\text {*** }}$

37.4

$26.1^{* * *}$

6.3

$4.0^{*}$

4.7

1.1

1.8

NA

NA

3.2

\section{Awareness of consent procedures}

Misperceiving that a woman undergoing abortion needs her husband's consent

96.1

$75.7^{* * *}$

97.9

$87.5^{* * *}$

\section{B. Multivariate results (Odds ratio, DiD estimate) ${ }^{1}$}

Holds multiple misperceptions (5-6 of 6 conditions $)^{2,3}$

$0.73(0.53-0.99)^{*}$

Misperceives that a women undergoing abortion needs her husband's consent ${ }^{2,3}$

$0.86(0.47-1.57)$

${ }^{*} p<=0.05 ;{ }^{* *} p<=0.01 ;{ }^{* * *} p<=0.001$

${ }^{1}$ Odds ratios less than 1.0 imply a positive net effect.

${ }^{2}$ Controlling age, years of education attained, total number of children ever born, standard of living index and experience of one or more abortions.

${ }^{3}$ Excludes awareness of two conditions; for a married woman to access abortion and if the foetus is a female. 
effects. No discernible effect was detected in terms of percentages misperceiving that abortion is illegal in at least one valid condition (not shown in table); however, findings suggest that the intervention had a significant net effect on reducing percentages holding multiple misperceptions-DiD coefficient $0.73(0.53-0.99)$. The intervention also appeared to reduce, but not significantly, misperceptions about consent procedures.

\section{Summary}

Findings suggest that there was a significant increase, between the year prior to the baseline and the year prior to the endline, in the percentage of women in Tonk who were exposed, through any source, to information on abortion; in comparison, the corresponding increase in Bundi was mild. While the leading source of information for women in both districts was the mass media, that is, television, radio, newspapers, magazines, and in Tonk, docu-dramas, community radio shows, posters and billboards that formed a major part of the BCC intervention, the increase in Tonk was greater than that in Bundi. As far as the content of communication is concerned, the leading message reported by more than half of all women in both districts related to restrictions on sexselective abortion. However, women in Tonk were significantly more likely than their counterparts in Bundi to report messages relating to the availability of medical abortion (36\% versus $23 \%$ ) and the availability of abortion services in public health facilities ( $25 \%$ versus $12 \%$ ), and significantly less likely to report messages about abortion being illegal or wrong (1\% versus $6 \%)$.

Changes in awareness of various aspects of abortion varied by district. For example, awareness of surgical abortion increased significantly (by 13 percentage points) in Tonk, but remained unchanged in Bundi. Awareness that abortion is available at PHCs and $\mathrm{CHCs}$ increased significantly in both districts (by 17 and 22 percentage points, respectively). Misperceptions that abortion is illegal in at least one valid condition fell more steeply in Bundi than in Tonk-by 19 compared to 10 percentage points. However, misperceptions that abortion is illegal in almost all the six conditions posed fell significantly in both districts, but more steeply in Tonk than in Bundi (by 9 compared to 4 percentage points). Likewise, misperceptions regarding consent procedures fell significantly in both settings, but more steeply in Tonk than in Bundi (20\% versus $10 \%)$.

Findings highlight, finally, that the intervention had a significant positive effect on awareness of surgical abortion, and a significant negative net effect on misperceptions held by women about conditions under which abortion is legal, notably misperceptions about most of the six valid conditions in which abortion is legal. 


\section{CHAPTER 6}

\section{Experiences of women who underwent abortion}

As mentioned earlier, the longer term objectives of the district-level CAC model were to increase women's access to safe abortion from the public sector and reduce unsafe aspects of abortion, including delayed abortion and resort to multiple providers. This chapter explores the progress made in the short period under observation in these practices, among women whose abortion had taken place in the three years preceding the base- and end-line interviews. We start with a word of caution. The numbers of women who underwent abortion in the three years preceding each survey were very small, making interpretation difficult; findings must be interpreted as illustrative and not conclusive.

\section{Prevalence of abortion: Lifetime and recent}

Table 6.1 shows that $3-5 \%$ of women in both Tonk and Bundi had undergone an abortion at least once in the three years preceding the baseline and endline interviews. District-wise patterns suggest that the percentages who had experienced an abortion were similar at both points in time: $3-4 \%$ in Tonk and $4-5 \%$ in Bundi. The abortion ratio, that is, abortions per 100 live births, increased from 7 to 10 in Tonk, and fell from 12 to 9 in Bundi.

\section{Abortion-related experiences}

We focus in this section on such abortion-related experiences of women as the abortion provider, facility, and the method of abortion used. It also assesses the extent to which practices such as second trimester and repeat abortions prevailed.

In both districts, the majority of women who had experienced a recent abortion reported that their abortion had been conducted by an allopathic doctor (Table 6.2). While percentages so reporting at baseline and endline remained largely unchanged

\section{Table 6.1}

Prevalence of abortion in the three years preceding the interview, Tonk and Bundi districts, Rajasthan

\begin{tabular}{|c|c|c|c|c|}
\hline & \multicolumn{2}{|c|}{ Tonk } & \multicolumn{2}{|c|}{ Bundi } \\
\hline & Baseline & Endline & Baseline & Endline \\
\hline Number of women & 940 & 922 & 1,013 & 925 \\
\hline $\begin{array}{l}\text { Prevalence of abortion in } t \\
\text { interview }\end{array}$ & & & & \\
\hline Experienced abortion (\%) & 2.7 & 3.8 & 4.9 & 3.8 \\
\hline Abortion ratio ${ }^{1}$ & 7.1 & 9.7 & 12.1 & 9.2 \\
\hline
\end{tabular}

Note: Differences between baseline and endline values are not significant.

${ }^{1}$ Abortions per 100 live births. 
in Tonk (from 84 to 80 ), they fell from 92 to 80 in Bundi. In Tonk, about one-third of the women reported that their abortions had been conducted at local-level public sector facilities ( $\mathrm{PHC} / \mathrm{CHCs}$ ) and a roughly equal proportion reported the use of private sector facilities. However, while percentages using public sector facilities remained unchanged in Tonk (47-52\%), there was a notable decline in percentages accessing abortion from such facilities in Bundi (from 40 to 29), notably from the District Hospital (from 30 to 17). At endline, moreover, significant minorities of women in both districts reported the use of drugs purchased from chemists to induce abortion; percentages so reporting increased from 8 at baseline to 15 at endline in Tonk, and more so, from 2 to 14, respectively, in Bundi.

With regard to the method used for pregnancy termination, women were asked whether their abortion had been terminated using surgical or medical methods. In order to distinguish between MVA and D\&C, we asked women who reported surgical abortion whether they had been made unconscious (given general anaesthesia for the surgical procedure) or not (MVA). As mentioned earlier, we did not probe the nature of the oral medication taken at baseline and hence cannot confirm whether this was indeed the mifepristonemisoprostol combination or one of the many Ayurvedic and other preparations available.

Findings in Table 6.2 show a significant shift away from D\&C towards MVA and MA in both settings. Indeed, while at baseline, $56 \%$ and $88 \%$ of the women in Tonk and Bundi, respectively, who underwent an abortion in the three years prior to the interview reported that their abortion had been conducted using D\&C (surgery with general anaesthesia), by the time of the endline, this proportion had fallen significantly in both districts-to $38 \%$ and $43 \%$, respectively. At the same time, there were increases in percentages reporting MVA (surgery without general anaesthesia, using a syringe or 'pichkari)—from 20 to 32 in Tonk, and from 4 to 31 in Bundi-as well as in those reporting the use of medical abortion (abortion using pills)—from 16 to 27 in Tonk and from 4 to 23 in Bundi. The decline in percentages using $\mathrm{D} \& \mathrm{C}$, and correspondingly, increases in percentages of women reporting MVA or medical abortion were significant only in Bundi, likely attributable to the fact that even at baseline, abortion-seekers in Tonk were less likely to have used $\mathrm{D} \& \mathrm{C}$, and more likely to have used MVA and medical abortion than their counterparts in Bundi.

\section{Experiences of second trimester and repeat abortions}

As far as the timing of abortion is concerned, the large majority of women who underwent an abortion in the three years preceding the interview reported terminating their pregnancy in the first trimester. However, as shown in Table 6.3, while significant proportions of women (24-26\%)) in both districts reported a second trimester abortion at baseline, the proportions of such women fell between the baseand end-line surveys (to 15\% in Tonk and 9\% in Bundi). Also evident from Table 6.3 is the finding that $6-9 \%$ of women whose most recent abortion had taken place in the three years prior to the interviews, reported an additional abortion during the same period. 


\section{Table 6.2}

Percentage of women by facility/individual who conducted the abortion and abortion method used, among women who underwent abortion in the three years preceding the interview, Tonk and Bundi districts,

Rajasthan

\begin{tabular}{|c|c|c|c|c|}
\hline & \multicolumn{2}{|c|}{ Tonk } & \multicolumn{2}{|c|}{ Bundi } \\
\hline & Baseline & Endline & Baseline & Endline \\
\hline $\begin{array}{l}\text { Number of women who underwent an abortion in the three } \\
\text { years preceding the interview }\end{array}$ & 25 & 34 & 50 & 35 \\
\hline \multicolumn{5}{|l|}{ Facility/individual who conducted the abortion } \\
\hline Public sector or private sector (allopathic) & 84.0 & 79.5 & 92.0 & 80.0 \\
\hline Public sector & 52.0 & 47.1 & 40.0 & 28.6 \\
\hline District Hospital & 16.0 & 14.7 & 30.0 & 17.1 \\
\hline $\mathrm{PHC/CHC}$ & 36.0 & 32.4 & 10.0 & 11.4 \\
\hline Private sector (allopathic) & 32.0 & 32.4 & 52.0 & 51.4 \\
\hline Uncertified providers & 16.0 & 20.6 & 8.0 & 20.0 \\
\hline Nurse/ANM & 8.0 & 0.0 & 6.0 & 5.7 \\
\hline Chemist & 8.0 & 14.7 & 2.0 & 14.3 \\
\hline Dai/TBA $1 /$ herbalist/other traditional practitioner & 0.0 & 5.9 & 0.0 & 0.0 \\
\hline \multicolumn{5}{|l|}{ Method of abortion used } \\
\hline Surgery with general anaesthesia & 56.0 & 38.2 & 88.0 & $42.9^{* * *}$ \\
\hline Surgery without general anaesthesia & 20.0 & 32.4 & 4.0 & $31.4^{* *}$ \\
\hline Pills (medical abortion) & 16.0 & 26.5 & 4.0 & $22.9^{*}$ \\
\hline Injections & 8.0 & 0.0 & 4.0 & 0.0 \\
\hline $\begin{array}{l}\text { Herbs/roots/foreign bodies/homemade concoction/ } \\
\text { Ayurvedic medicines }\end{array}$ & 0.0 & 2.9 & 0.0 & 2.9 \\
\hline
\end{tabular}

${ }^{*} p<=0.05 ;{ }^{* *} p<=0.01 ;{ }^{* * *} p<=0.001$

${ }^{1}$ Dai or TBA: traditional birth attendant.

\section{Table 6.3}

Percentage of women reporting multiple and second trimester abortions, among women who underwent abortion in the three years preceding the interview, Tonk and Bundi districts, Rajasthan

\begin{tabular}{|c|c|c|c|c|}
\hline & \multicolumn{2}{|c|}{ Tonk } & \multicolumn{2}{|c|}{ Bundi } \\
\hline & Baseline & Endline & Baseline & Endline \\
\hline $\begin{array}{l}\text { Number of women who underwent an abortion in the } \\
\text { three years preceding the interview }\end{array}$ & 25 & 34 & 50 & 35 \\
\hline Women reporting second trimester abortion ${ }^{1}$ & 24.0 & 14.7 & 26.0 & $8.6^{*}$ \\
\hline $\begin{array}{l}\text { Women reporting repeat abortions during the three years } \\
\text { preceding the interview }{ }^{1}\end{array}$ & 8.0 & 8.8 & 6.0 & 8.6 \\
\hline
\end{tabular}

${ }^{1}$ Differences between baseline and endline values are not significant. 


\section{Summary}

The longer term objectives of the district-level CAC model were to increase women's use of abortion facilities in the public sector and reduce unsafe aspects of abortion, including delayed and repeat abortions, and hence, findings shed light on progress made in the short period under observation in changing these practices, among women whose abortion took place in the three years preceding the baseline and endline interviews. By and large, the findings confirm that changes have been modest but illustrative.

In total, $3-5 \%$ of women in Tonk and Bundi had experienced an abortion in the three years prior to the baseline and endline surveys; abortion ratios of 7-12, correspondingly, were observed. There was little change in the percentages of women reporting repeat abortions, but a considerable decline was observed in both districts, in second trimester abortions. Although the majority of abortions continued to take place in public sector facilities, while percentages remained around $50 \%$ in Tonk, there was a notable decline at endline, in the use of public sector facilities, notably the District Hospital, in Bundi (from 30 to 17). There was also an increase in abortions induced by using oral medication purchased directly from a chemist-from $8 \%$ to $15 \%$, respectively, at baseline and endline, in Tonk and correspondingly, from $2 \%$ to $14 \%$, in Bundi. Findings also suggest an impressive shift from D\&C to both MVA and medical abortion in both districts, although significant only in Bundi, likely the result of the fact that even at baseline, abortionseekers in Tonk were less likely to have used D\&C, and more likely to have used MVA and medical abortion than their counterparts in Bundi. 


\section{CHAPTER 7}

\section{Summary and conclusions}

This chapter summarises the major findings of the study and highlights key lessons learned for programming to increase access to comprehensive abortion care.

\section{Summary}

The district-level Comprehensive Abortion Care model had several objectives. It focused on increasing the availability of services, through extensive training of providers in public sector facilities and ensuring that facilities were equipped with the necessary infrastructure and equipment to enable the provision of abortion services. At the same time, the intervention aimed to increase awareness among women and communities, more generally, about abortion-related issues, including the conditions under which it is legal, women's right to access abortion, the types of abortion available and the location of abortion services. Finally, the longer term objectives were to increase women's access to abortion in public sector facilities, and improve the experiences of abortion-seekers in terms of, for example, a reduction in second trimester and repeat abortions and a shift from D\&C to MVA and medical abortion. Longer term objectives in public sector facilities such as an increase in post-abortion contraceptive counselling and contraceptive uptake, a reduction in post-abortion complications, and an improvement in the quality of care experienced by abortion-seekers, are not assessed in this report.

The intervention was conducted in more than half of all public sector facilities and among the rural areas served by these facilities in one district of Rajasthan, Tonk. A quasi-experimental research design, with cross-sectional surveys undertaken in all PHCs and CHCs, and in villages in which community level activities were conducted in the intervention district, Tonk, and in a neighbouring control district, namely Bundi, prior to the implementation of the intervention and at its conclusion, was used to evaluate the effects of the intervention. Intervention activities were implemented in a phased manner, with facility-based activities conducted over a 17 -month period (March 2008 to July 2009) and community-based activities over a 12-month period (April 2009 to March 2010), with actual engagement with women taking place over just a five-month period (November 2009 to March 2010) due to reasons described in Chapter 3. The evaluation focused on married women aged 15-39, that is, those most likely to have experienced a recent pregnancy, and was conducted among a total of 940 and 1,013 women in Tonk and Bundi, respectively, at the time of the baseline survey in 2007, and among 922 and 925 women, respectively, at the time of the endline survey in 2010 .

Findings highlight that at the time of the baseline survey, the availability of abortion services was limited; indeed, not a single PHC offered abortion services and women's access to abortion services was further compromised by a host of factors including poor awareness of their right to avail services, long distances to facilities and substantial costs. Also evident was the poor quality of abortion-related care. Given this context, and 
given the short duration of implementation, the changes achieved by the intervention are promising.

\section{Facility-level effects}

Facility-level effects were measured largely by process indicators. Findings indicate that the intervention had a considerable effect on increasing the availability of safe abortion services in public sector facilities. Indeed, while at baseline, not a single PHC in either of the two districts provided abortion services, almost one-fifth of all PHCs in Tonk, compared to not a single PHC in Bundi were providing abortion services at the time of the endline survey. At the same time, as a result of the focus on provider training in the intervention, there was a far more striking increase in the availability of MTP-certified providers in Tonk than in Bundi: at the PHC level, for example, an increase of 36 and 8 percentage points, respectively. At the $\mathrm{CHC}$ level, too, the number of facilities with a certified MTP provider increased from five to seven in Tonk; in contrast, there was no change in the number of trained MTP-certified providers at the $\mathrm{CHC}$ level in the two districts.

While trained providers were more likely to be available in Tonk, improvement in provider awareness about the conditions to be met for performing abortions were inconsistent over the period of the intervention. Improvements in provider awareness about women's abortion-related rights, however, were more evident. By the time of the endline survey, for example, all providers in both districts acknowledged the right of women to confidential counselling, and most also respected women's right to be informed about the procedure she is to undergo, though providers in Tonk were more likely than those in Bundi to do so.

The effect of the intervention was also evident in terms of increases in displays of IEC materials on the legality and availability of abortion. While such materials were much more evident in facilities at endline than baseline in both settings, the increase was far more evident in Tonk (from $2 \%$ to $93 \%$ of all $\mathrm{PHCs}$, and from four to seven $\mathrm{CHCs}$ ) than in Bundi (from $4 \%$ to $0 \%$, and in one $\mathrm{CHC}$ at both times). In addition, improvements in functioning essential equipment required for the provision of abortion increased by 11 percentage points in Tonk and 7 percentage points in Bundi.

Because of the increase in the number of PHCs providing abortion, there was a considerable increase, in total, in the number of abortions conducted. For example, in the year preceding the endline assessment, PHCs in Tonk had conducted in total, 107 abortions, and an average of eight per facility. There was, in addition, a considerable increase in the number of abortions conducted at the CHC level in Tonk: from 281 in the year preceding the baseline survey to 1,178 in the year preceding the endline survey. In the CHCs of Bundi, in contrast, there was a major decline, from 390 to 42 in the years preceding the base- and end-line surveys.

Findings also suggest that at the time of the endline assessment, two PHCs in Tonk were using $\mathrm{D} \& \mathrm{C}$ for first trimester abortions; in contrast, four of the seven CHCs in Tonk and one of the two in Bundi continued to do so. The use of medical abortion was limited in both districts: just one each 
of the eight PHCs and five CHCs, respectively, in Tonk offered medical abortion, compared to one of the two CHCs in Bundi.

The intervention-in terms of facility strengthening and provider training-was implemented in more than half of all the PHCs of Tonk. While at the time of the endline survey, slightly less than one-fifth of all PHCs in Tonk were providing abortion services, a comparison of indicators in intervention and non-intervention PHCs in Tonk further underscores the role of the intervention. By the time of the endline survey, onethird of the intervention PHCs and all CHCs were providing abortion services, compared to none of the non-intervention PHCs and two of the six CHCs. Likewise, the availability of trained providers, IEC materials and functioning essential equipment for the provision of abortion services were systematically more available in intervention than non-intervention facilities.

\section{Community-level effects}

Findings suggest that there was a significant increase, between the year prior to the baseline and the year prior to the endline, in the percentage of women from Tonk who were exposed, through any source, to information on abortion; in comparison, the corresponding increase in Bundi was mild. While the leading source of information for women in both districts was the mass media, that is, television, radio, newspapers, magazines, and in Tonk, docu-dramas, community radio programmes, posters and billboards that formed a major part of the BCC intervention, the increase in Tonk was greater than that in Bundi. As far as the content of communication is concerned, the leading message reported by more than half of all women in both districts related to restrictions on sexselective abortion. However, women in Tonk were significantly more likely than their counterparts in Bundi to report messages relating to the availability of medical abortion and the availability of abortion services in public health facilities.

Changes in women's awareness of various aspects of abortion varied by district. For example, awareness of surgical abortion increased significantly (by 13 percentage points) in Tonk, but remained unchanged in Bundi. Awareness that abortion is available in peripheral public sector facilities increased significantly in both districts (by 17 and 22 percentage points, respectively). Misperceptions that abortion is illegal in at least one valid condition fell more steeply in Bundi than in Tonk-by 19 compared to 10 percentage points. However, misperceptions that abortion is illegal in almost all the six conditions posed fell significantly in both districts, but more steeply in Tonk than in Bundi (by 9 compared to 4 percentage points). Likewise, misperceptions regarding consent procedures fell significantly in both settings, but more steeply in Tonk than in Bundi (21\% versus 10\%). Findings highlight, nonetheless, that the intervention had a significant net positive effect on awareness of surgical abortion, and a significant negative net effect on two key indicators reflecting misperceptions held by women about conditions under which abortion is legal: misperceptions about most of the six valid conditions in which abortion is legal, and misperceptions about consent procedures. 
The longer term objectives of the districtlevel CAC model were to increase women's use of abortion facilities in the public sector and reduce unsafe aspects of abortion, including delayed and repeat abortions, and hence findings shed light on progress made in the short period under observation in changing these practices, among women whose abortions took place in the three years preceding the base and endline interviews. By and large, findings confirm that changes have been modest but illustrative.

In total, 3-5\% of women in Tonk and Bundi had experienced an abortion in the three years prior to the baseline and endline surveys, respectively; abortion ratios of 7-12, correspondingly, were observed. There was little change in the percentage of women reporting repeat abortions, but a considerable decline in both districts, in second trimester abortions. The majority of abortions continued to take place in public sector facilities; however, while percentages remained unchanged in Tonk, there was a notable decline in the use of public sector facilities, notably the District Hospital, in Bundi. There was also an increase in abortions using oral medication purchased directly from a chemist, from eight to $15 \%$ in Tonk and from $2 \%$ to $14 \%$ in Bundi. Findings also suggest that there was an impressive shift from D\&C to MVA/MA, with the use of both MVA and medical abortion increasing impressively in both districts.

\section{Limitations}

Our study has several limitations that may have affected the effects of the intervention. The most prominent of these is the duration of the intervention. The intervention was implemented over a short period of time: facility-level activities were conducted over 17 months, and community-level activities over 12 months, with active engagement with the community lasting just five months. This period included such start up activities as the establishment of a training site and training providers (each training activity lasted about three weeks and included no more than three medical officers), setting up a facility-monitoring mechanism, designing the $\mathrm{BCC}$ campaign, including the development of BCC/IEC materials, and identifying local NGO partners and training their staff to implement the community-based component. A 12-month period was likely insufficient to effect major changes, particularly those involving changes in practices (such as abortion-seeking in the second trimester, preference for private sector facilities). As a result, again, observed effects are likely to be conservative, and in some instances, for example, quality of care in public sector facilities and postabortion contraception or morbidity among women undergoing abortion in public sector facilities, could not be assessed.

A second limitation is the possible diffusion of intervention effects into the control district. For example, training of providers and upgrading of facilities to enable the provision of abortion took place, in the course of the project, in neighbouring districts including Bundi, under the state government. At the same time, materials prepared for the intervention were increasingly deployed for BCC in other districts, including Bundi. These factors may have reduced the net effect of the intervention, and the effects observed must therefore be acknowledged as conservative. 
Finally, we acknowledge that over the period of the intervention, substantial general health sector changes took place; for example, the implementation of the National Rural Health Mission and the introduction of the Janani Suraksha Yojana; the inclusion of a new cadre of workers, namely the ASHAs, and liberalisation of medical abortion procedures enabling the provision of medical abortion at the PHC level if an appropriate referral facility was available. All of these programmatic changes may have influenced the availability of services and community-level awareness of abortion services in both districts. Thus, notwithstanding our efforts to distinguish the effect of the intervention after controlling for confounding factors, it may be difficult to attribute changes entirely to the intervention.

\section{Recommendations}

Several lessons can be drawn from the experience of implementing the Comprehensive Abortion Care model, which could be relevant for its modification and up-scaling. These are outlined below:

\section{Targeting the most-at-risk}

Findings suggest that the awareness building component of the intervention succeeded in reaching a large number of women, as well as in reducing the upholding of large numbers of misperceptions about valid conditions under which abortion is legal, and raising awareness of MVA, for example. Nevertheless, awareness levels were far from universal or comprehensive. Evidence suggests that while community-level awareness building efforts are useful, they are not sufficient and messages need to be targeted to those most at risk of needing an abortion. One such group, easily available to the health sector, is women seeking other reproductive health services such as pregnancy-related care, contraception, or for concerns about menstruation and other sexual health matters. Efforts must be made to inform these women when they seek services (and those who accompany them, if possible), about the availability of abortion should the need arise, the conditions under which it is legal and illegal, the methods by which it is conducted, and the public sector facilities in which it is available.

\section{Shifting preferences for abortion services to the public sector}

Findings have suggested that while awareness that PHCs and CHCs provide abortion has increased considerably, and notwithstanding data on the increase in the number of abortions conducted at these facilities in Tonk, just half of the women who underwent an abortion in the period between the baseline and endline surveys had used a public sector facility for their abortion and just one-third had used a PHC or CHC. Reasons may include, among others, a lack of awareness about the availability of abortion at peripheral public sector facilities, perceptions about poor quality of services at public facility level, or the persistence of misperceptions at endline (albeit significant declines from baseline), with a large majority of women continuing to believe that the husband's consent is mandatory. It is important that the health system take steps to inform communities about the availability and quality of abortion services. 


\section{Extending interventions to the private sector}

Notwithstanding efforts to make abortion services available in the public sector, our evidence has underscored that considerable proportions of women preferred to seek abortion in the private sector. It is important that issues relating to service quality and quality of care, respect for women's rights and an emphasis on post-abortion contraceptive counselling are provided to women seeking abortion in the private sector. Models are needed that incorporate the private sector in the provision of abortion in rural areas, and ensure that the services provided are of good quality.

\section{From access to quality services}

Findings have highlighted the success of the intervention in raising awareness about quality of care among medical officers of PHCs and CHCs as well as improving the readiness of health facilities to provide safe abortion services. This is perhaps one of the most significant aspects of the intervention. It is important now to ensure that women who avail of abortion services from public sector facilities do indeed experience care of good quality and respect for their reproductive rights; in this context, incorporating a component on quality of care, including post-abortion contraceptive counselling, and women's reproductive rights within abortion training programmes is central. The importance of quality of services and care needs to be emphasised, and monitoring activities must focus as much on assessing quality of care, post-abortion contraception, and respect for women's rights as they do to assessing numbers of abortion conducted.

\section{Integration of facility-and community-based components}

Findings suggesting a disconnect between various facility- and community-based activities, highlight the need for greater integration between the facilitypreparedness and the demand generation processes. Health system outreach workers as well as NGO outreach workers must be made responsible, for example, for informing women about safe abortion, supporting those in need to reach an appropriate facility and following up those who have undergone an abortion to monitor side-effects and address postabortion contraception. At the same time, activities are needed that strengthen the capacity of nongovernmental organisations and other civil society mechanisms to monitor health system activities and demand the services that are due to communities.

In brief, the findings from this evaluation are encouraging in many respects, notwithstanding a number of challenges faced. The district-level CAC model did indeed succeed in strengthening facilities, training providers and increasing women's access to safe abortion services at the PHC level. Communitylevel activities were less successful, attributable to a considerable extent to the short duration during which community engagement took place. Both the facility- and the community-based components were feasible to implement and can be integrated into existing government services without much additional investment. 


\section{References}

Ashenfelter, O. 1978. "Estimating the effect of training programs on earnings", Review of Economics and Statistics 60(1):47-57.

Ashenfelter, O and D. Card. 1985. "Using the longitudinal structure of earnings to estimate the effect of training programs", Review of Economics and Statistics 67(4):648-60.

Barge, S., M. E. Khan, S. Rajagopal et al. 1998. "Availability and quality of MTP services in Gujarat, Maharashtra, Tamil Nadu and Uttar Pradesh," Paper presented at the Global Meeting on Post-abortion Care and Operations Research, organised by Population Council, New York.

Barge, S., H. Bracken, B. Elul et al. 2004. Formal and Informal Abortion Services in Rajasthan, India: Results of a Situation Analysis. New Delhi: Population Council.

Barua, A. and H. Apte. 2007. "Quality of abortion care: perspectives of clients and providers in Jharkhand," Economic and Political Weekly 42(48):71-80.

Chhabra, R. and S.C. Nuna. 1994. Abortion in India: An Overview. New Delhi: Ford Foundation.

Duggal, R. and S. Barge. 2004. "Abortion services in India: Report of a multicentric enquiry". Abortion Assessment Project-India. Mumbai: CEHAT/Healthwatch.

Elul, B., S. Barge, S. Verma et al. 2004. Unwanted Pregnancy and Induced Abortion: Data from Men and Women in Rajasthan, India: Report. New Delhi: Population Council.

Ganatra, B. R. 2000. "Abortion research in India: What we know and what we need to know," in Women's Reproductive Health in India, eds. R. Ramasubban and S. Jejeebhoy. Jaipur: Rawat Publications.

Ganatra, B. R., S. Hirve, S. Karvande et al. 2008. "Induced abortions in rural western Maharashtra: Prevalence and patterns," in Reproductive Health in India: New Evidence, eds. M. Koenig, S. Jejeebhoy, J. Cleland and B. Ganatra. New Delhi: Rawat Publications.

Government of India. 1971. The Medical Termination of Pregnancy Act (Act. No. 34). New Delhi: Government of India.

Government of India. 2003. The Medical Termination of Pregnancy Rules (Amendment). New Delhi: Government of India.

International Institute for Population Sciences (IIPS). 2006. District Level Household Survey (DLHS-2), 2002-04: India. Mumbai: IIPS.

International Institute for Population Sciences (IIPS) and ORC Macro. 2000. National Family Health Survey (NFHS-2), 1998-99: India. Mumbai: IIPS. 
International Institute for Population Sciences (IIPS) and Population Council. 2010. Youth in India: Situation and Needs, 2006-2007. Mumbai: IIPS.

Jejeebhoy S.J., A. J. F. Zavier and S. Kalyanwala. 2010. Assessing Abortion-related Experiences and Needs in Four Districts of Maharashtra and Rajasthan, 2006. New Delhi: Population Council.

Kalyanwala, S., A. J. F. Zavier and S. Jejeebhoy. 2010. Public Health Facilities and Women's Access to Abortion: A Situation Analysis in Maharashtra and Rajasthan. New Delhi: Population Council (unpublished report).

Malhotra, A., L. Nyblade, S. Parasuraman et al. 2003. Realizing Reproductive Choice and Rights: Abortion and Contraception in India. Report. Washington DC: International Council for Research on Women.

Ministry of Health and Family Welfare (MOHFW). 2000. National Population Policy 2000. New Delhi: Department of Family Welfare, MOHFW, Government of India.

Ministry of Health and Family Welfare (MOHFW). 2001. Guidelines for Medical Officers for Medical Termination of Pregnancy upto eight weeks using Manual Vacuum Aspiration Technique. New Delhi: Maternal Health Division, MOHFW, Government of India.

Ministry of Health and Family Welfare (MOHFW). 2005. National Rural Health Mission: Meeting People's Health Needs, Framework for Implementation 2005-2012. New Delhi: MOHFW, Government of India.

Ministry of Health and Family Welfare (MOHFW). 2010. Annual Report 2009-10. New Delhi: Department of Health and Family Welfare, MOHFW, Government of India.

Office of the Registrar General, India (RGI). 2006. Sample Registration System, Maternal Mortality in India: 1997-2003 Trends, Series I, Causes and Risk Factors. New Delhi: RGI.

Office of the Registrar General and Census Commissioner. 2004. Primary Census Abstract: Total Population: Table A-5. New Delhi: Office of the Registrar General and Census Commissioner.

Saha, S., R. Duggal and M. Mishra. 2004. Abortion in Maharashtra: Incidence, Care and Cost. Abortion Assessment Project India. Mumbai: CEHAT/Healthwatch.

World Health Organization. 2003. Safe Abortion: Technical and Policy Guidance for Health Systems. Geneva, World Health Organization. 

Population Council
Zone 5-A, Ground Floor
India Habitat Centre
Lodi Road
New Delhi 110 003, India

Population Council
Zone 5-A, Ground Floor
India Habitat Centre
Lodi Road
New Delhi 110 003, India

Population Council
Zone 5-A, Ground Floor
India Habitat Centre
Lodi Road
New Delhi 110 003, India

Population Council
Zone 5-A, Ground Floor
India Habitat Centre
Lodi Road
New Delhi 110 003, India

in

in

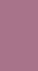

